\title{
Title:
}

\section{Hepatitis E Virus Lifecycle and Identification of 3 Forms of the ORF2 Capsid Protein}

\section{Short title:}

New insights into HEV lifecycle

\section{Authors:}

Claire Montpellier ${ }^{\mathrm{a}, \#}$, Czeslaw Wychowski ${ }^{\mathrm{a}, \#}$, Ibrahim M. Sayed ${ }^{\mathrm{b}, \mathrm{c}}$, Jean-Christophe Meunier ${ }^{\mathrm{d}}$, JeanMichel Saliou $^{\mathrm{a}}$, Maliki Ankavaya ${ }^{\mathrm{a}}$, Anne Bull ${ }^{\mathrm{d}}$, André Pillez ${ }^{\mathrm{a}}$, Florence Abravanel ${ }^{\mathrm{e}}$, François Helle ${ }^{\mathrm{f}}$, Etienne Brochot ${ }^{\mathrm{f}}$, Hervé Drobecq $^{\mathrm{g}}$, Rayan Farhat ${ }^{\mathrm{a}}$, Cécile-Marie Aliouat-Denis ${ }^{\mathrm{a}}$, Juliano G. Haddad ${ }^{\mathrm{a}}$, Jacques Izopet $^{\mathrm{e}}$, Philip Meuleman ${ }^{\mathrm{b}}$, Anne Goffard $^{\mathrm{a}}$, Jean Dubuisson ${ }^{\mathrm{a}}$, Laurence Cocquerel ${ }^{\mathrm{a}}$

${ }^{a}$ University of Lille, CNRS, INSERM, CHU Lille, Pasteur Institute of Lille, U1019-UMR8204-CIILCenter for Infection and Immunity of Lille, F-59000 Lille, France

${ }^{\mathrm{b}}$ Laboratory of Liver Infectious Diseases, Department of Clinical Chemistry, Microbiology and Immunology, Ghent University, Ghent, Belgium.

${ }^{\mathrm{c}}$ Microbiology and Immunology Department, Faculty of Medicine, Assiut University, Assiut, Egypt.

${ }^{d}$ Inserm-U966, University F. Rabelais, F-37032 Tours, France.

${ }^{\mathrm{e}} \mathrm{CHU}$ Toulouse, Hôpital Purpan, Laboratoire de virologie, National Reference Center for Hepatitis E, F-31300, France.

${ }^{\mathrm{f}}$ EA4294, Laboratoire de Virologie, Centre Universitaire de Recherche en Santé, Centre Hospitalier Universitaire et Université de Picardie Jules Verne, Amiens, France

${ }^{\mathrm{g}}$ Univ. Lille, CNRS, Institut Pasteur de Lille, UMR 8161-M3T-Mechanisms of Tumorigenesis and Target Therapies, Lille, France.

${ }^{\#} \mathrm{CM}$ and $\mathrm{CW}$ contributed equally to this work

\section{Grant Supports:}

This work was supported by the French "Agence Nationale de la Recherche sur le Sida et les hépatites virales" (ANRS) and the University of Lille. M. A. was supported by a fellowship from the ANRS. P.M was supported by grants from the Research Foundation Flanders (FWO Vlaanderen), Ghent University (BOF GOA and IRO), and the Belgian State (BELSPO IAP HEPRO-2). I.M.S was supported with PhD fellowships from the Egyptian Government and Ghent University. J.G.H was supported by a fellowship from the Lebanese Association for Development. 
Abbreviations:

aa, amino acid; Ag, antigen; BFA, brefeldin A; DMEM, Dulbecco's modified Eagle's medium; DT, sodium deoxycholate and trypsin treatment; EndoH, endoglycosidase H; ER, endoplasmic reticulum; FCS, fetal calf serum; ffu, focus forming unit; GLuc, Gaussia luciferase; GNA, Galanthus nivalis agglutinin; gt, genotype; $\mathrm{HCV}$, hepatitis $\mathrm{C}$ virus; $\mathrm{HEV}$, hepatitis E virus; HEVcc, cell culture-produced HEV particles; HEV ser, HEV particles from patient serum; IC, immunocapture; MAb, monoclonal antibody; nanoLC-MS/MS, nano scale Liquid Chromatography coupled to tandem Mass Spectrometry; Neura, neuraminidase; O-Gly, O-glycosidase; ORFs, open reading frames; PBS, phosphate buffered saline; p.e., post-electroporation; $\mathrm{PHH}$, primary human hepatocytes; PNGaseF, peptide-N-glycosidase F; RLU, relative luciferase unit; RT-qPCR, real-time-quantitative polymerase chain reaction; SD, standard deviation; SFV, Sofosbuvir; SP, signal peptide; TEM, transmission electron microscopy; WB, western blotting.

\section{Correspondence:}

Dr Laurence Cocquerel, Molecular \& Cellular Virology, CIIL, CNRS-UMR8204 \& Inserm-U1019, Institut Pasteur de Lille, Bâtiment IBL, 1 rue du Pr. Calmette, CS50447, 59019 Lille cedex, France. E-mail: laurence.cocquerel@ibl.cnrs.fr

Dr Czeslaw Wychowski, Molecular \& Cellular Virology, CIIL, CNRS-UMR8204 \& Inserm-U1019, Institut Pasteur de Lille, Bâtiment IBL, 1 rue du Pr. Calmette, CS50447, 59019 Lille cedex, France. E-mail: czeslaw.wychowski@ibl.cnrs.fr

\section{Disclosures:}

All authors disclose no conflicts.

\section{Author contributions:}

Conceived and designed the experiments: CM, CW, IMS, JCM, JMS, MA, AB, AP, PM, JD, LC. Performed the experiments: CM, CW, IMS, JCM, JMS, MA, AB, AP, HD, JGH, LC. Analyzed the data: CM, CW, IMS, JCM, JMS, PM, JD, LC. Contributed reagents/materials/analysis tools: FA, FH, EB, RF, CMAD, JI, PM, AG. Wrote the paper: LC.

\section{Word count:}

Main text (Abstracts -Introduction-M\&M-Results-Discussion-References): 7007 


\section{Abstract}

Background \& Aims: Hepatitis E virus (HEV) infection is a major cause of acute hepatitis worldwide. Approximately 2 billion people live in areas endemic for HEV and are at risk of infection. The HEV genome encodes 3 proteins, including the ORF2 capsid protein. Detailed analyses of the HEV lifecycle has been hampered by the lack of an efficient viral culture system.

Methods: We performed studies with gt $3 \mathrm{HEV}$ cell culture-produced particles (HEVcc) and patient blood and stool samples. Samples were fractionated on iodixanol gradients and cushions. Infectivity assays were performed in vitro and in human liver chimeric mice. Proteins were analyzed by biochemical and proteomic approaches. Infectious particles were analyzed by transmission electron microscopy. HEV antigen levels were measured with the Wantaï ELISA.

Results: We developed an efficient cell culture system and isolated HEV particles that were infectious in vitro and in vivo. Using transmission electron microscopy, we defined the ultrastructure of HEVcc and particles from patient sera and stool samples. We also identified the precise sequence of the infectious particle-associated ORF2 capsid protein. In cultured cells and in samples from patients, HEV produced 3 forms of the ORF2 capsid protein: infectious/intracellular ORF2 (ORF2i), glycosylated ORF2 (ORF2g), and cleaved ORF2 (ORF2c). The ORF2i protein associated with infectious particles, whereas the ORF2g and ORF2c proteins were massively secreted glycoproteins not associated with infectious particles. ORF2g and ORF2c were the most abundant antigens detected in sera from patients.

Conclusions: We developed a cell culture system and characterized HEV particles; we identified 3 ORF2 capsid proteins (ORF2i, ORF2g, and ORFc). These findings will advance our understanding of the HEV lifecycle and improve diagnosis.

KEY WORDS: Hepatitis E, PLC/PRF/5 cells, infectious particles, ORF2 products 


\section{Introduction}

Hepatitis E virus (HEV) is the leading cause of enterically transmitted viral hepatitis globally, and is responsible for 20 million infections and 70,000 deaths every year ${ }^{1}$. Though HEV infection is usually self-resolving, severe forms or chronic infections have been described, mainly in immunocompromised patients. A high rate of mortality has also been reported among pregnant women. HEV infection has also been associated with extrahepatic disorders, including renal and neurological disorders ${ }^{2}$. Four genotypes (gt) are pathogenic in humans. Gt 1 and gt 2 exclusively infect humans, while gt 3 and gt 4 are zoonotic and mainly infect animals that may transmit the virus to humans. Recently, gt 3 infections have been emerging in the Western world, likely due to contaminated blood transfusions and the consumption of contaminated food ${ }^{1}$. The diagnosis of hepatitis $\mathrm{E}$ is based on the detection of anti-HEV antibodies and/or viral RNA in patient serum ${ }^{3}$. Recently, a new assay based on detecting the HEV capsid protein antigen was developed (Wantaï Biologicals), especially for laboratories with no molecular diagnosis facilities.

HEV is a quasi-enveloped, positive-sense RNA virus expressing three open reading frames (ORFs): ORF1, ORF2 and ORF3 ${ }^{1}$. ORF1 encodes the ORF1 non-structural polyprotein, which contains several functional domains essential for viral replication. ORF2 encodes the ORF2 viral capsid protein, which is involved in particle assembly, binding to host cells and eliciting neutralizing antibodies. ORF3 encodes a small multifunctional phosphoprotein involved in virion morphogenesis and egress. Although HEV is a non-enveloped virus in bile and feces, patient serum and cell cultureproduced particles have been described to be associated with cellular lipids, as for Hepatitis A virus ${ }^{4}$, and display the ORF3 protein at their surface ${ }^{5}$.

The growth of HEV in cell culture has been proven to be very difficult ${ }^{5}$. However, several HEV strains have been adapted to cell culture, including the gt 3 Kernow C-1 strain, which contains an insertion of a 58-aa human S17 ribosomal protein ${ }^{6}$. Although these systems have led to increased understanding of the HEV lifecycle, they still produce low infectious titers, limiting direct biochemical analysis of viral proteins and infectious material. Notably, the exact sequence of infectious particleassociated ORF2 protein is unknown. In addition, the ultrastructure of particles has never been robustly studied by immune electron microscopy.

In our study, we describe an HEV cell culture system that leads to early and massive expression of viral proteins and infectious particles, permitting their direct biochemical analysis. For the first time, we define the ultrastructure of HEV particles by electron microscopy and identify the precise sequence of the infectious particle-associated ORF2 capsid protein. We demonstrate that in infected cell culture and patients, at least three forms of the ORF2 capsid protein are produced. The two major ORF2 proteins are not associated with infectious particles, despite being the major antigens present in HEVinfected patient sera. 
Chemicals and cell cultures. PLC/PRF/5 (CRL-8024), PLC1, PLC3 and A549 (CCL-185) cells were grown in Dulbecco's modified Eagle's medium (DMEM) supplemented with 10\% inactivated fetal calf serum (DMEM/FCS) at $37^{\circ} \mathrm{C}$. Transfected cells were maintained at $32^{\circ} \mathrm{C}$ in a medium containing DMEM/M199 (1v:1v), 1mg/ml of lipid-rich albumin (Albumax $\mathrm{I}^{\mathrm{TM}}$ ) and 40nM Na $2 \mathrm{SeO}_{3}$.

Plasmids and transfection. Plasmids expressing the cell culture adapted gt 3 Kernow C-1 strain (HEV-p6, GenBank accession number JQ679013) or the replicon expressing the Gaussia luciferase gene (HEV-p6GLuc) were provided by S.U Emerson ${ }^{6}$. The replication-deficient replicon HEVp6GLucGAD was generated by mutating the GDD motif into the RNA-dependent RNA polymerase gene ${ }^{7}$. Capped RNA transcripts were generated with the mMESSAGE mMACHINE® kit (Ambion). Capped RNAs were delivered to cells by electroporation using a Gene Pulser Xcell ${ }^{\mathrm{TM}}$ apparatus (BioRad).

\section{Kinetics experiments and virus production.}

PLC1 and PLC3 cells were electroporated with capped HEV-p6 RNA ( $20 \mu \mathrm{g} / 4 \times 10^{6}$ cells). For kinetics experiments, every two days, supernatants were harvested and cells were lysed in buffer containing 50mM TrisHCl (pH 7.5), 150mM NaCl, 5mM EDTA, 0.5\% (v/v) NP40, 0.05\% sodium deoxycholate, $1 \mathrm{mM}$ PMSF and protease inhibitor cocktail (Complete; Roche). For virus production, cells were split every 10 days. Supernatants were collected and stored at $-80^{\circ} \mathrm{C}$.

Density gradients. PLC3/HEV-p6 supernatant was concentrated with a Vivaspin ultrafiltration spin column (Sartorius). Concentrated supernatant or patient serum $(500 \mu \mathrm{l})$ was layered on a 7.5-40\% iodixanol gradient, which was centrifuged at $160,000 \mathrm{~g}$ for $16 \mathrm{~h}$ at $4{ }^{\circ} \mathrm{C}$. Twelve fractions of $1 \mathrm{ml}$ were collected and their density was measured by refractometry. The HEV RNA titer was determined by RT-qPCR. Each fraction was used to infect A549 cells. Infectivity was determined by indirect immunofluorescence, immunoblotting, and RNA and viral titration. For patient samples, fractions were used for ORF2 probing, GNA pull-down, and RNA quantification.

\section{Purification of infectious particles on iodixanol cushion. Supernatant of PLC3/HEV-p6 was} concentrated by centrifugation through a $20 \%$ iodixanol cushion at $160,000 \mathrm{~g}$ for $4 \mathrm{~h}$ at $4{ }^{\circ} \mathrm{C}$. The cushion was resuspended in PBS, ultracentrifuged a second time, and the pellet was resuspended in PBS. 
Infection of humanized mice. Primary human hepatocytes were transplanted into homozygous $\mathrm{uPA}^{+/+}-\mathrm{SCID}$ mice, as previously described ${ }^{8}$. Humanized mice were inoculated via intrasplenic route with HEV-p6 purified on iodixanol gradient (fraction6, F6p6, 8.7 $110^{7} \mathrm{IU} / \mathrm{mouse}$ ) or with the same volume of fraction6 from a control gradient prepared with concentrated supernatant of non-transfected PLC3 cells (F6 control). Non-transplanted mice inoculated with these preparations served as negative controls. A chimeric mouse inoculated with a gt 1 (Sar55, 2.8 $\times 10^{5} \mathrm{IU} / \mathrm{mouse}$ ) stool suspension was used as a positive control ${ }^{9}$. Stool and plasma samples were collected on a weekly basis. Viral RNA was detected and quantified in mouse plasma and stool using RT-qPCR, as described ${ }^{9}$. Detection of ORF1 and ORF2 in F6p6 mouse samples was performed as described in the supplementary material. Sequencing of the $\mathrm{S} 17$ region was performed as described ${ }^{9}$.

Transmission electron microscopy (TEM). The formvar-carbon TEM grids (S162, Oxford Instruments) were either incubated with $0.01 \%$ poly-L-lysine for $30 \mathrm{~min}$ at room temperature (RT) or with poly-L-lysine and then with anti-ORF3 (Bioss antibodies), anti-ORF2 (1E6), or isotype-matched antibodies $(20 \mu \mathrm{g} / \mathrm{ml})$ for $1 \mathrm{~h}$ at RT. Grids were washed in PBS and incubated for $2 \mathrm{~h}$ at RT with viral samples. TEM grids were washed in PBS and incubated for $20 \mathrm{~min}$ in $4 \%$ paraformaldehyde and $1 \%$ glutaraldehyde in $0.1 \mathrm{M}$ phosphate buffer, $\mathrm{pH} 7.2$. Particles trapped on grids were stained with $0.5 \%$ uranyl acetate before examination under a JEOL-1230 TEM. For delipidation, particles were either treated for $1 \mathrm{~h}$ at $37^{\circ} \mathrm{C}$ with $1 \%$ sodium deoxycholic acid, $0.1 \%$ trypsin, then processed for TEM, or treated in the same conditions then layered on an iodixanol gradient. After determining density and RNA levels, fraction 11 was processed for TEM.

Glycosidase digestions. Protein samples were denaturated for $10 \mathrm{~min}$ at $95^{\circ} \mathrm{C}$ in glycoprotein denaturing buffer (New England Biolabs). Digestions with glycosidases were carried out for $4 \mathrm{~h}$ at $37^{\circ} \mathrm{C}$ in the presence of $1 \%$ NP40 and the buffer provided by the manufacturer (NEB). Samples prepared in the same conditions but without glycosidase were used as controls.

GNA pull-down. Agarose-conjugated GNA beads were incubated for $2 \mathrm{~h}$ at RT with $50-500 \mu \mathrm{l}$ of patient serum or $100 \mu \mathrm{l}$ of supernatant of PLC3/HEV-p6. Beads were washed 8 times with PBS $0.5 \%$ NP40. Proteins were eluted in Laemmli Buffer and analyzed by SDS-PAGE. Unconjugated agarose beads were used as a negative control.

Patient samples. Patient samples were collected in France between 2012 and 2016. This was a noninterventional study. Samples were obtained only via standard viral diagnostics following a physician's order (no supplemental or modified sampling). Data were analyzed anonymously. The 
1 French Public Health Law (CSP Art L 1121-1.1) does not require written informed consent from

2 patients for such a protocol.

$\frac{1}{3}$

3 Detection of HEV-Ag. Gradient fractions were diluted in PBS and Ag levels were measured with the 5 Wantaï HEV-Ag ELISA ${ }^{\text {Plus }}$ kit (Wantaï Biological Pharmacy Enterprise) according to the 6 manufacturer's instructions. 


\section{Establishment of an efficient HEV cell culture system}

In an attempt to establish a cell culture system for HEV, we first analyzed HEV replication in two subclones of the PLC/PRF/5 cell line, namely PLC1 and PLC3 cells. We used the Gaussia luciferase (GLuc)-expressing HEV gt3 replicon named HEV-p6GLuc ${ }^{6}$, in which the ORF2 coding sequence was replaced with the secreted GLuc sequence. Thus, the amount of secreted GLuc is proportional to viral RNA synthesis and consequently to HEV replication. PLC1, PLC3, and parental PLC/PRF/5 cells were electroporated with HEV-p6GLuc RNA or with a non-replicative HEV-p6GLuc genome (HEV-p6GLucGAD). The replication levels of HEV-p6GLuc steadily increased over time in the three cell lines (Figure 1A), but PLC1 and PLC3 cells showed higher HEV replication fold increase, as compared to PLC/PRF/5 cells. Experiments were thereafter conducted using PLC1 and PLC3 cells.

We assessed the ability of PLC1 and PLC 3 cells to express viral proteins and produce infectious particles in kinetics experiments. PLC1 and PLC3 cells were electroporated with the HEVp6 RNA strain ${ }^{6}$. Immunofluorescence with anti-ORF2 and anti-ORF3 antibodies showed that over $80 \%$ of cells expressed viral proteins (Figure 1B), indicating that PLC1 and PLC3 cells are highly transfectable, and that robust replication and expression of viral genome likely occur in these cells. It must be noted that ORF2 expression was inhibited in the presence of Sofosbuvir (SFV) (Figure S1), confirming the specificity of the signal.

We next analyzed the expression of ORF2 and ORF3 proteins in the cell lysates and supernatants of HEV-p6 electroporated PLC1 and PLC3 cells by western blotting (WB) at different time points. Importantly, the ORF2 protein was detected in the cell lysates and supernatant of PLC1 cells as early as 2 and 4 days post-electroporation (p.e.), respectively (Figure 1C). In HEV-p6 electroporated PLC3 cells, expression of the ORF2 protein was slightly delayed. It must be noted that PLC3 cells grow more slowly than PLC1 cells, which could explain the observed differences. In addition to the major product of ORF2, ORF2-related proteins with lower molecular weights were also detected in cells and supernatants, indicating that the ORF2 capsid protein likely undergoes posttranslational modifications. The ORF3 protein was also early detected at 2 and 4 days p.e. in PLC1 and PLC3 cell lysates, respectively (Figure 1C). In contrast, the ORF3 protein was faintly detected in the supernatants of electroporated cells, indicating that this protein is mainly expressed intracellularly.

The major ORF2 product in the supernatant (Figure 1D, Sup) displayed a higher apparent molecular weight than the intracellular form (Figure 1D, Cells), suggesting that the highly secreted ORF2 protein likely undergoes post-translational modifications. Comparison of intracellular and extracellular ORF3 proteins showed that the secreted ORF3 protein migrated slightly faster than the 
intracellular protein (Figure 1D) likely reflecting differences in protein phosphorylation ${ }^{10}$ or undescribed modifications of the ORF3 protein.

Viral RNA and infectious particles were also monitored in the supernatants of transfected cells collected on different days p.e. HEV RNA levels were assessed by RT-qPCR. High RNA levels were detected as early as 2 days p.e. (Supplementary Table 1). RNA titers increased progressively and reached $1.1 \times 10^{8}$ and $3.3 \times 10^{7}$ copies/ml at day 10 for PLC1 and PLC 3 cells, respectively (Supplementary Table 1). In parallel, infectious viral titers were determined and reached $7 \times 10^{3}$ and $1.5 \times 10^{3} \mathrm{ffu} / \mathrm{ml}$ for PLC1 and PLC3 cells, respectively. These results indicate that assembly of infectious viral particles occurs very early and equally in HEV-p6 electroporated PLC1 and PLC3 cells. However, HEV infectivity represents $1.5 \times 10^{4}$ RNA copies/ffu for PLC1 cells and $2.2 \times 10^{4}$ RNA copies/ffu for PLC3 cells, indicating that the assembly of infectious HEV particles is likely an inefficient process. However, we cannot exclude the possibility that a viral or cellular inhibitor blocks HEV infection and biases the infectious titers. Further experiments were carried out using PLC3 cells.

\section{ORF2 capsid protein is massively produced but only a small fraction is assembled into infectious} particles.

To produce large amounts of infectious supernatants, we cultured HEV-p6 transfected PLC3 cells during 47 days. Supernatants were pooled, concentrated, and fractionated on an iodixanol gradient. The distribution of ORF2 protein, ORF3 protein, RNA and infectious viral particles was analyzed from each fraction (Figure 2). ORF2 protein was detected from fractions 2 to 7 but more abundantly in fractions 3 to 5 (Figure 2A). As observed in the supernatants of transfected cells (Figure 1C), ORF2 protein in fractions 2 to 5 was detected as two products, one major product of approximately 90kDa (ORF2g) and a smaller product of around 75kDa (ORF2c). ORF2-related proteins with lower molecular weights were also detected at the top of the gradient in fractions 2 to 5 , which might correspond to additional processed forms of the proteins. In contrast, the ORF2 protein was mainly detected as an 80kDa product (ORF2i) in fractions 6 and 7, which corresponds to the size of intracellular ORF2 (Figure 1C). The ORF3 protein was exclusively detected in fractions 5 to 7 but most abundantly in fraction 6 (Figure 2A). Interestingly, only one major peak of RNA was detected in fraction 6, with a density of $1.10 \mathrm{~g} / \mathrm{ml}$ (Figure 2B). Therefore, a large amount of capsid protein (fractions 2 to 4) was not associated with the viral RNA while the ORF3 protein was.

The infectivity of each fraction was analyzed by infecting A549 cells. Expression of ORF2 and ORF3 proteins was analyzed by WB (Figure 2C) and indirect immunofluorescence (Figure 2D and data not shown) five days post-infection. ORF2i and ORF3 proteins were detected in the lysates of cells infected with fractions 5, 6 and 7 (Figure 2C), suggesting that infectious particles were associated with these fractions. Indeed, immunofluorescence staining of A549 cells inoculated with fractions 5, 6 and 7 were positive for ORF2 protein expression whereas cells inoculated with fractions 
1 to 4 and fractions 8 to 12 were negative (Figure 2D and data not shown). Fraction 6 showed the highest infectious titer $\left(5 \times 10^{6} \mathrm{ffu} / \mathrm{ml}\right)$. While ORF2g and ORF2c proteins were detected in cells inoculated with fractions 3 and 4 (Figure 2C), no specific infection was observed with these fractions by immunofluorescence (data not shown), indicating that ORF2g and ORF2c are likely very stable proteins binding to the cell surface that can be detected after several days of incubation.

It must be noted that the exosomal CD81 tetraspanin was detected in infectious fractions (Figure 2A), supporting the hypothesis that HEV particles likely exploit the exosomal secretory pathway for their egress ${ }^{11}$.

Together, our results indicate that during the HEV lifecycle, the ORF2 capsid protein is massively produced, but only a small fraction (ORF2i) is assembled into infectious particles that are secreted through the exosomal pathway.

\section{Infection of human liver chimeric mice with HEVcc particles.}

Recently, human liver chimeric mice have been described as valuable models for studying in vivo chronic HEV infection and evaluating antiviral molecules 9,12-14. Establishment of HEV infection in chimeric mice was achieved after inoculation of gt 1 or gt 3 virions. However, inoculation of mice with non-treated cell culture supernatant-derived particles did not result in robust infection. Therefore, we next evaluated whether our HEVcc particles were able to infect primary human hepatocyte (PHH)transplanted mice ${ }^{9}$. Chimeric mice were inoculated via intrasplenic route with either fraction 6 of HEV-p6 (F6p6) purified on iodixanol gradient (Figure 2) or fraction 6 of a control gradient prepared from non-transfected PLC3 cells supernatant (F6 control, neg 1) (Figure 3). A human chimeric mouse inoculated with a gt1 stool suspension (Sar55) was used as a positive control ${ }^{9}$. A non-transplanted mouse inoculated with F6p6 was used as a second negative control (neg 2). While to a lesser extent than the gt1-infected mouse, the F6p6-inoculated chimeric mouse still showed signs of active infection (Figure 3). Indeed, HEV RNA was detected in stools of F6p6-inoculated chimeric mouse from week 2 to 10 with a significant increase from week 8 to 10 (Figure $\mathbf{3 A}$ and $\mathbf{3 B}$ ). Genomic HEV RNA was also detected in mouse liver (Figure 3C) and small intestine content (Figure 3D). RNA load in the F6p6inoculated mouse increased more slowly as compared to the gt1-inoculated mouse, as previously described ${ }^{9}$ but for the first time, we demonstrate a robust infection of a chimeric mouse inoculated with HEV particles derived from cell culture supernatant.

Since HEV-p6 strain contains the human S17 ribosomal protein fragment that confers a growth advantage ${ }^{6,15}$, we next sequenced this region of HEV-p6 from the F6p6-infected mouse (stool week 9 p.i. and one liver piece) and compared it to the inoculum. We did not find any reversion of adaptive mutations in the $\mathrm{S} 17$ region (data not shown). 
Ultrastructure of HEV particles.

Recently, a new strategy based on the direct specific immunocapture (IC) of hepatitis C virus (HCV) particles on transmission electron microscopy (TEM) grids led, for the first time, to the precise description of their ultrastructure ${ }^{16}$. To define the morphology of HEVcc particles, which has never been precisely described, we used the same approach on isolated infectious particles. We first analyzed material captured on grids coated with poly-L lysine, a polycationic attachment factor. We observed a fairly homogeneous population of particles of 40-70nm in size (Figure 4A). We next performed IC with an antibody specific to the ORF3 protein that had been described as exposed on lipid-associated HEV particles. We observed particles with an apparent internal icosahedral substructure likely corresponding to the capsid (Figure 4A). The calculation of size distribution showed that particle sizes ranged from $40 \mathrm{~nm}$ to $70 \mathrm{~nm}$. In contrast, no particles were observed when an anti-ORF2 (1E6) (Figure 4A) or isotype control antibodies (data not shown) were used. However, when viral preparation was first partially delipidated by sodium deoxycholate and trypsin (DT) treatment before IC with the antiORF2 antibody, two populations of particles were immunocaptured: a major population consisting of particles of 30-50nm in size and a more heterogeneous population with particles of 90-140nm (Figure 4B). Thus, DT treatment unmasked the 1E6 epitope on viral particles and led to IC of small HEV particles that likely correspond to naked virions. However, DT treatment did not fully remove ORF3 and associated lipids since some particles were still captured by an anti-ORF3 antibody (Figure 4B). The larger size of these particles is likely due to dissociation of their lipid coats. In contrast, when DTtreated particles were purified on density gradient before IC (Figure 4C, Fraction F11), a highly homogeneous population of particles of approximately $32 \mathrm{~nm}$ was immunocaptured with 1E6 while no particles were captured by IC anti-ORF3. These particles, with a density of $1.18 \mathrm{~g} / \mathrm{ml}$, displayed an icosahedral structure likely corresponding to naked capsids.

We next analyzed the ultrastructure of authentic particles from three HEV-infected patient sera (HEVser). As for HEVcc, no particles were observed by IC anti-ORF2 or IC with irrelevant antibodies (data not shown). In contrast, IC anti-ORF3 resulted in the efficient isolation of pleomorphic populations. HEVser1 and HEVserST-1 particles had a similar morphology to HEVcc particles while HEVser2 particles displayed a thick outer layer likely corresponding to lipids (Figure 5A). The calculation of size distribution of immunocaptured particles showed that the mean and median diameters of HEVser particles were generally larger than those of HEVcc particles and differed between patients (Figure 5B). Particles from HEV ser2 were the largest with a mean diameter of $120 \mathrm{~nm}$. These results suggest that additional components, which could be the lipid content of particles, likely determine particle size, as described for HCV particles ${ }^{16}$. However, further investigations will be needed to further characterize HEV particles from patients.

Lastly, we analyzed the ultrastructure of stool particles from the ST-1 HEV-infected patient. In contrast to HEVcc and HEVser, stool particles were captured by IC anti-ORF2, whereas no particles 
were captured by IC anti-ORF3 (Figure 5C). Although particles appeared to be entangled in impurities limiting calculation of size distribution, the mean diameter of HEV stool particles was $28 \mathrm{~nm}$, which is in accordance with previous observations ${ }^{17}$. As for delipidated HEVcc, stool particles displayed an icosahedral structure likely corresponding to naked capsids. No particles were captured from non-infected patient stools.

\section{Characterization of the different forms of ORF2 protein.}

We developed a purification system using a $20 \%$ iodixanol cushion to easily separate infectious particles (ORF2i, Figure 6A, Pellet) from ORF2g/ORF2c proteins that are not associated with infectious particles (Figure 6A, Top).

HEV produces large amounts of secreted ORF2g/ORF2c proteins that are likely glycosylated/processed forms of the ORF2 protein. In contrast, infectious particle-associated ORF2 protein (ORF2i) purified by iodixanol gradient (F6p6) or cushion (Pellet/Cushion) displayed the same size as intracellular ORF2 protein (Cells) (Figure 6B), indicating that ORF2i likely does not undergo post-translational modifications.

Since the ORF2 protein sequence contains three potential sites for N-linked glycosylation and multiple sites for O-linked glycosylation, we next analyzed the sensitivity of ORF2 proteins to treatment with different glycosidases (Figure 6C). Endoglycosidase H (EndoH) cleaves within the chitobiose core of high mannose and some hybrid oligosaccharides from N-glycoproteins. Peptide-NGlycosidase F (PNGaseF) cleaves between the innermost $\mathrm{N}$-acetyl glucosamine and asparagine residues of high mannose, hybrid and complex oligosaccharides from N-glycoproteins. O-Glycosidase (O-Gly) catalyzes the removal of some O-linked disaccharides. Neuraminidase (Neura) catalyzes the hydrolysis of sialic acid residues from $\mathrm{N}$ - and O-glycoproteins. It should be noted that terminal sialic acids block the action of O-Gly. The ORF2i protein expressed from cell lysates or purified HEV particles was resistant to glycosidase digestions (Figure 6C), indicating that this protein is not N- or O-glycosylated. In contrast, secreted ORF2g/ORF2c proteins were sensitive to digestion with EndoH and PNGaseF glycosidases, as attested by the mobility shift upon treatment, indicating that these proteins are $\mathrm{N}$-glycoproteins. ORF2g/ORF2c proteins were resistant to O-Gly treatment but sensitive to treatment with Neura and more markedly to a combination of Neura and O-Gly. These results indicate that ORF2g/ORF2c proteins are sialylated and O-glycosylated proteins. Importantly, ORF2g/ORF2c proteins were precipitated by a Galanthus Nivalis Agglutinin (GNA) pull-down, a lectin that interacts with high-mannose-type glycans confirming the oligomannosidic nature of ORF2g/ORF2c N-glycans (Figure 6D) and allowing the easy and specific precipitation of ORF2g/ORF2c proteins.

We demonstrated that secreted ORF2g/ORF2c are glycosylated proteins, indicating that these proteins go through the secretory pathway. However, ORF2g/ORF2c proteins were not detected at the 
intracellular level. We therefore hypothesized that ORF2g/ORF2c proteins might move rapidly through the secretory pathway and be secreted quickly without intracellular accumulation. We thus treated HEV-p6 expressing PLC3 cells with Brefeldin A (BFA), a protein secretion inhibitor ${ }^{18}$ (Figure 6E). Upon BFA treatment, secretion of ORF2g/ORF2c proteins was blocked. Interestingly, a diffuse band likely corresponding to ORF2g and a faint band likely corresponding to ORF2c were detected in the lysate of BFA-treated cells, indicating that upon protein secretion blocking, $\mathrm{ORF} 2 \mathrm{~g} / \mathrm{ORF} 2 \mathrm{c}$ proteins accumulate in the cell, thus validating our hypothesis.

We next analyzed the sequence of ORF2 proteins by mass spectrometry. Viral particles purified on iodixanol cushion and ORF2g/ORF2c proteins immunoprecipitated with an anti-ORF2 antibody (4B2) were resolved by SDS-PAGE. The Colloïdal blue stained bands corresponding to ORF2i, ORF2g and ORF2c in WB (Figure S2) were digested in-gel with trypsin or AspN and then analyzed by nanoLC-MS/MS. Identified peptides and sequence covering are shown in Figure S2. For the three proteins, the C-terminal end was fully covered, demonstrating the absence of processing at their C-termini. For ORF2i protein, a semi-tryptic peptide covering half of the signal peptide (SP) was unexpectedly identified (Figure S2A, dashed line), suggesting that the SP of ORF2i might not be cleaved. For ORF2g, tryptic and semi-AspN peptides starting with $\mathrm{Ser}^{34}$ were identified, suggesting that the first aa of the ORF2g protein might correspond to $\operatorname{Ser}^{34}$ (Figure S2B). For ORF2c, tryptic peptides starting with Iso ${ }^{234}$ were identified, suggesting that the first aa of the ORF2c protein might correspond to one of the aa in proximity to $\operatorname{Iso}^{234}$ (Figure S2C). Since semi-tryptic and semi-AspN peptides correspond to either natural protein processing or non-specific proteolytic events during proteomics analyses, we further performed labeling with $\mathrm{N}$-succinimidyloxycarbonylmethyl tris (2,4,6-trimethoxyphenyl) phosphonium bromide (TMPP-Ac-OSu), which binds specifically to the Nterminus of intact proteins ${ }^{19}$. Peptides identified with TMPP-Ac-OSu modification confirmed that the first aa of ORF2i and ORF2g corresponds to $\mathrm{Leu}^{14}$ and $\mathrm{Ser}^{34}$, respectively (Figures $\mathbf{6 F}, \mathbf{S 2}$ and $\mathbf{S 3}$ ). In contrast, as TMPP-Ac-OSu labeling did not identify the first aa of ORF2c, further studies are necessary to clarify this observation. Together, these data indicate that the ORF2g protein loses its SP and is likely processed by secretory pathway proteases. In contrast, the ORF2i protein is not processed by a signal peptidase and therefore likely not translocated into the ER lumen.

\section{ORF2g/ORF2c proteins are the major antigens in HEV-infected patient sera}

Since we demonstrated that in cell culture, HEV mainly produces glycosylated forms of ORF2 proteins that are not associated with infectious particles, we next sought to determine whether the same occurs in infected patients. Sera from ten chronically infected HEV patients and from five HEVnegative patients were precipitated by GNA pull-down and probed for the ORF2 protein (Figure 7A), as described above. GNA-pulldown of PLC3/HEV-p6 supernatant was used as a positive control. Strikingly, 8 and 5 out of $10 \mathrm{HEV}$-positive sera displayed large amounts of the ORF2g and ORF2c 
1 proteins, respectively. ORF2 proteins were not detected in HEV-negative sera. In addition, the

2 detection of ORF2g/ORF2c proteins was dependent neither on the patient's HEV strain nor on the

1 serum viral load (Supplementary Table 2). Importantly, fractionation of a patient serum (P6 patient)

3 on an iodixanol gradient followed by GNA pull-down of each fraction (Figure 7B) demonstrated that, as in cell culture, very large amounts of ORF2g/ORF2c proteins were isolated in light fractions (fractions 4 and 5) and pull-down by GNA. However, these fractions were not associated with infectious material, since they were not associated with the viral genome (Figure 7C). It should be noted that the ORF2 proteins present in fraction 4 were likely not precipitated by GNA beads due to the presence of high amounts of human albumin. Our results indicate that ORF2g/ORF2c proteins are likely the major antigens in HEV-infected patient sera. Therefore, we quantified ORF2 proteins in each fraction of the gradient with the Wantaï HEV-antigen ELISA ${ }^{\text {Plus }}$ assay (Figure 7D). Interestingly, the highest amount of antigen was detected in fraction 4, containing the ORF2g/ORF2c proteins, whereas lower amounts of antigens were detected in the other fractions and notably in fraction 7 , the infectious fraction. Together, our results indicate that in infected patients, HEV produces high amounts of glycosylated antigen protein that are not associated with infectious particles and might lead to a bias in diagnosis of active HEV infection. 


\section{Discussion}

By combining the highly replicative and cell culture-adapted p6 strain ${ }^{6}$ and highly transfectable subclones of PLC/PRF/5 cells, we developed a new cell culture system for which viral replication and protein expression were detected very early post-transfection. Time-course experiments showed that the ORF2 protein was early and massively secreted into the supernatant of transfected cells, as recently reported ${ }^{20,21}$. Interestingly, ORF2 and ORF3 proteins migrated differently when detected either in cell lysate or supernatant, indicating that these proteins likely undergo posttranslational modifications during their secretion. Further experiments would be necessary to identify such modifications in the ORF3 protein. The ORF2 protein contains three potential sites for N-linked glycosylation and multiple sites for O-linked glycosylation. Using expression vectors, it has been previously shown that the ORF2 protein is glycosylated and expressed on the cell surface ${ }^{22-24}$, but it is not clear whether the glycosylated ORF2 protein is the natural form of the virion. Recently, it has been suggested that the HEV virion capsid is likely glycosylated ${ }^{20}$, although Graff et al. showed the opposite ${ }^{25}$. Our study revealed that HEV produces large amounts of ORF2 proteins, named ORF2g and ORF2c, that are secreted, sialylated, N- and O-glycosylated but are not associated with infectious virions. A large portion of ORF2 proteins is likely translocated into the ER lumen where they are Nglycosylated and likely processed by proteases to generate ORF2g and ORF2c proteins. These two proteins move rapidly through the secretory pathway where they are O-glycosylated and sialylated, then quickly secreted. Interestingly, the presence of RGRR residues upstream of the ORF2g Nterminus suggests that a furin-like protease might be involved in its maturation. Further experiments would be necessary to characterize glycosylation and processing sites in the ORF2 sequence, notably the mechanism leading to the production of the ORF2c protein. In contrast, the ORF2i protein seen on an intracellular level and in virions is likely not translocated into the ER lumen and stays in the cytosolic compartment. Our results suggest the existence of two production pathways for the HEV capsid protein: (i) a major non-productive pathway in which ORF2 proteins are delivered to the secretion route where they are processed and quickly secreted. (ii) a productive pathway in which cytosolic ORF2 proteins are delivered to the virion assembly sites. Further studies are needed to thoroughly investigate these pathways.

In contrast to previous studies ${ }^{9,13}$, we succeeded in infecting chimeric mice with gt 3 HEVcc particles. The separation of infectious particles from ORF2g/ORF2c proteins by density gradient might explain our success, as these proteins interfere with the capacity of virions to infect target cells (Figure S4), using a mechanism which needs to be elucidated.

We found that during its lifecycle, HEV highly secretes glycosylated forms of the ORF2 protein, which circulate in infected patients and are the major antigens in patient sera. It would be interesting to define which form of ORF2 protein is recognized by antibodies from patients that have resolved their infections. HEV may produce ORF2g/ORF2c proteins as immunological bait. 
Interestingly, using TEM analyses, we found that ORF2g/ORF2c proteins do not form particulate material (data not shown) in contrast to other viruses such as hepatitis B virus, where the surface antigen forms subviral particles.

Our TEM analyses showed that HEVcc are particles of 40-70nm in size displaying internal structures and the ORF3 protein at their surface. DT treatment and ultracentrifugation uncloaked small icosahedral capsids similar to those found in patient stools ( ${ }^{17}$ and our study), indicating that HEVcc are associated with lipids in which ORF3 is embedded. Our analyses showed that, although much larger, HEVser particles have a morphology similar to HEVcc particles. HEVser virions display the ORF3 protein at their surface and are likely highly associated with lipids. As HEVser diameters differed between patients, it would be interesting to determine if the observed size variations are related to lipid content, as recently demonstrated for HCV particles ${ }^{16}$.

Recently, the Wantaï HEV-Ag-ELISA assay was marketed for diagnosing HEV infection. Comparative studies of this assay showed high levels of specificity and sensitivity ${ }^{26-29}$. However, some discrepancies between antigen detection and RNA quantification were found in some samples in which the HEV antigen was detected in the absence of detectable RNA ${ }^{27-29}$. In our hands, the antigen assay was also very sensitive. However, we found that ORF2g/ORF2c proteins, which are not associated with infectious virions, were the main antigens recognized by the kit. Together, these data indicate that the results obtained with the HEV-Ag-ELISA assay must be cautiously interpreted. Indeed, this assay might not necessarily detect an active infection, since ORF2g/ORF2c proteins seem to be very stable in cell culture but likely also in patient sera ${ }^{28}$, suggesting that these proteins might remain in patient sera even when HEV is no longer replicating in the liver. 
Figure 1: HEV replication and protein expression in transfected PLC/PRF/5-derived cells. (A) PLC/PRF/5, PLC1 and PLC3 cells were electroporated with the HEV-p6Gluc replicon. For each time point, values are presented as fold increase compared to luciferase activities measured at $24 \mathrm{~h}$ postelectroporation (p.e.). Activities were normalized to intracellular activities. Data are representative of three independent experiments. (B) PLC1 and PLC3 cells were transfected with the infectious HEV-p6 RNA. Five days p.e., ORF2 (red) and ORF3 (green) protein expression was analyzed by immunofluorescence. Nuclei are shown in blue. (C) ORF2 and ORF3 protein expression in cell extracts and supernatants at different time points p.e. (D) ORF2 and ORF3 protein expression in cell extracts and supernatants harvested at 10 days p.e..

\section{Figure 2: Density gradient of HEV-p6 transfected PLC3 cell supernatant. Concentrated} PLC3/HEV-p6 cell supernatant was layered on an iodixanol gradient and ultracentrifuged. Twelve fractions were collected and their densities were measured. (A) Expression of ORF2, ORF3 and CD81 proteins analyzed by WB. (B) HEV RNA levels in each fraction measured by RT-qPCR. A549 cells were infected with an aliquot of each fraction. Five days post-infection, protein expression was analyzed by WB in infected cell lysates (C) and by immunofluorescence (D). For clarity, only some infections are shown.

Figure 3: Infection of humanized mice with HEVcc. PHH-transplanted mice were inoculated by intrasplenic route with either fraction 6 of HEV-p6 purified on iodixanol gradient (F6p6) or fraction 6 of a control gradient prepared from the supernatant of non-transfected PLC3 cells (F6 control, neg1). A human chimeric mouse inoculated with a gt1 (Sar55) stool suspension was used as a positive control. A non-transplanted mouse inoculated with F6p6 was used as a second negative control (neg2). (A) The levels of plus strand-HEV RNAs (IU/ml) were quantified by RT-qPCR in mouse stools and plasma at different time points after inoculation. Standard deviations (SD) were omitted for clarity. LOQ, limit of quantification. Detection of RNAs by using ORF1 primers in mice stools (B) and liver (C). Stool CTL p6 was from a chimeric mouse inoculated with a p6 cell lysate ${ }^{9}$. (D) Detection of RNAs by using ORF2 primers. CTL, control; NTC, non-template control; wk, week; neg, negative; P1, piece 1; SI, small intestine.

Figure 4: Ultrastructure of HEVcc. Representative electron micrographs of particles immobilized on poly-L-lysine or immunocaptured (IC) with anti-ORF3 or anti-ORF2 antibodies. Histograms on the right show the immunocaptured particle size distribution for the indicated antibody. Mean, median and SD of particles diameter are indicated in the boxes. Grids were prepared with HEVcc (A) or with 
HEVcc treated with $1 \%$ sodium deoxycholic acid and $0.1 \%$ trypsin (DT) (B). In (C), DT-treated particles were purified on density gradient. The infectious fraction containing the highest level of HEV RNAs (F11) and with a density of $1.18 \mathrm{~g} / \mathrm{ml}$, was used for IC. Particles were stained with uranyl acetate dihydrate and observed using a JEOL-1230 electron microscope. Scale bars are indicated.

Figure 5: Ultrastructure of HEV particles from patient sera and stool. (A) Representative electron micrographs of IC anti-ORF3 with particles from three HEV-infected patient sera (HEVser). (B) Histograms show the immunocaptured particle size distribution. Mean, median and standard deviation (SD) of particle diameters are indicated in the boxes. (C) Representative electron micrographs of IC anti-ORF3 and IC anti-ORF2 of particles from HEV-infected patient stools (HEVstool) and noninfected patient stools (Stool neg). Scale bars and particle sizes are indicated.

Figure 6: Characterization of the different ORF2 products. (A) Detection by WB of ORF2 proteins in the top and pellet of the PLC3/HEV-p6 cell supernatant purified onto iodixanol cushion. (B) Comparison of ORF2 products expressed in the cell lysates and supernatant of PLC3/HEV-p6 cells, in infectious fraction 6 (F6p6) and non-infectious fraction 3 (F3p6) from iodixanol gradient, and in the pellet of PLC3/HEV-p6 cell supernatant purified on the iodixanol cushion. (C) PLC3/HEV-p6 cell lysate, supernatant and purified HEV particles were denatured and digested with indicated glycosidases (+) or not (-). The dashed line shows the migration shift of ORF2 proteins following glycosidase treatment. (D) ORF2 protein detection after incubation of the supernatant of PLC3/HEVp6 or PLC3 cells with GNA- or ProteinA-conjugated agarose beads. (E) PLC3/HEV-p6 cells were treated (+) or not (-) with Brefeldin A (BFA, 16h, 1 $\mathrm{gg} / \mathrm{ml})$ and the ORF2 protein expression in cells and supernatant was analyzed. (F) Sequence of ORF2 proteins analyzed by nanoLC-MS/MS. The dashed line corresponds to the signal peptide. Frames indicate potential N-glycosylation sites. The first aa of ORF2i and ORF2g identified by TMPP-Ac-OSu labeling are in bold.

Figure 7: ORF2g and ORF2c proteins are the major HEV antigens in infected patients. (A) GNA pull-down on patient sera followed by ORF2 probing. Pull-down of PLC3/HEV-p6 supernatant was used as a positive control. (B) Fractionation on iodixanol gradient (7.5-40\%) of the P6 patient serum and analysis of the ORF2 content of each fraction by WB and GNA pull-down. (C) HEV RNA levels in each fraction measured by RT-qPCR. (D) Detection of HEV Ag in each gradient fraction using the Wantaï HEV-Ag ELISA ${ }^{\text {Plus }}$ kit. Results are expressed as signal to cut-off ratios (S/CO). 


\section{References}

1. Debing Y, Moradpour D, Neyts J, et al. Update on hepatitis E virology: Implications for clinical practice. Journal of Hepatology 2016;65:200-212.

2. Pischke S, Hartl J, Pas SD, et al. Hepatitis E virus: Infection beyond the liver? Journal of Hepatology 2017;66:1082-1095.

3. Khuroo MS, Khuroo MS. Hepatitis E: an emerging global disease - from discovery towards control and cure. Journal of Viral Hepatitis 2016;23:68-79.

4. Feng Z, Hensley L, McKnight KL, et al. A pathogenic picornavirus acquires an envelope by hijacking cellular membranes. Nature 2013;496:367-371.

5. Okamoto H. Culture systems for hepatitis E virus. J Gastroenterol 2012;48:147-158.

6. Shukla P, Nguyen HT, Faulk K, et al. Adaptation of a genotype 3 hepatitis E virus to efficient growth in cell culture depends on an inserted human gene segment acquired by recombination. J Virol 2012;86:5697-5707.

7. Emerson SU, Nguyen $\mathrm{H}$, Graff J, et al. In vitro replication of hepatitis E virus (HEV) genomes and of an HEV replicon expressing green fluorescent protein. J Virol 2004;78:4838-4846.

8. Meuleman P, Libbrecht L, De Vos R, et al. Morphological and biochemical characterization of a human liver in a uPA-SCID mouse chimera. Hepatology 2005;41:847-856.

9. Sayed IM, Verhoye L, Cocquerel L, et al. Study of hepatitis E virus infection of genotype 1 and 3 in mice with humanised liver. Gut 2017;66:920-929.

10. Zafrullah M, Ozdener MH, Panda SK, et al. The ORF3 protein of hepatitis E virus is a phosphoprotein that associates with the cytoskeleton. J Virol 1997;71:9045-9053.

11. Nagashima S, Jirintai S, Takahashi M, et al. Hepatitis E virus egress depends on the exosomal pathway, with secretory exosomes derived from multivesicular bodies. Journal of General Virology 2014;95:2166-2175.

12. Allweiss L, Gass S, Giersch K, et al. Human liver chimeric mice as a new model of chronic hepatitis $E$ virus infection and preclinical drug evaluation. Journal of Hepatology 2016;64:1033-1040.

13. van de Garde MDB, Pas SD, van der Net G, et al. Hepatitis E Virus (HEV) Genotype 3 Infection of Human Liver Chimeric Mice as a Model for Chronic HEV Infection. J Virol 2016;90:4394-4401.

14. Sayed IM, Foquet L, Verhoye L, et al. Antiviral Research. Antiviral Research 2017;141:150154.

15. Shukla P, Nguyen HT, Torian U, et al. Cross-species infections of cultured cells by hepatitis E virus and discovery of an infectious virus-host recombinant. Proc. Natl. Acad. Sci. U.S.A. 2011;108:2438-2443.

16. Piver E, Boyer A, Gaillard J, et al. Ultrastructural organisation of HCV from the bloodstream of infected patients revealed by electron microscopy after specific immunocapture. Gut 2016.

17. Balayan MS, Andjaparidze AG, Savinskaya SS, et al. Evidence for a virus in non-A, non-B 
hepatitis transmitted via the fecal-oral route. Intervirology 1983;20:23-31.

18. Klausner RD, Donaldson JG, Lippincott-Schwartz J. Brefeldin A: insights into the control of membrane traffic and organelle structure. J Cell Biol 1992;116:1071-1080.

19. Gallien S, Perrodou E, Carapito C, et al. Ortho-proteogenomics: Multiple proteomes investigation through orthology and a new MS-based protocol. Genome Research 2008;19:128135.

20. Qi Y, Zhang F, Zhang L, et al. Hepatitis E Virus Produced from Cell Culture Has a Lipid Envelope. PLoS ONE 2015;10:e0132503.

21. Shiota T, Li TC, Yoshizaki S, et al. Establishment of hepatitis E virus infection-permissive and non-permissive human hepatoma PLC/PRF/5 subclones. Microbiol. Immunol. 2015;59:89-94.

22. Jameel S, Zafrullah M, Ozdener MH, et al. Expression in animal cells and characterization of the hepatitis E virus structural proteins. J Virol 1996;70:207-216.

23. Torresi J, Meanger J, Lambert P, et al. High level expression of the capsid protein of hepatitis E virus in diverse eukaryotic cells using the Semliki Forest virus replicon. J. Virol. Methods 1997;69:81-91.

24. Zafrullah M, Ozdener MH, Kumar R, et al. Mutational analysis of glycosylation, membrane translocation, and cell surface expression of the hepatitis E virus ORF2 protein. J Virol 1999;73:4074-4082.

25. Graff J, Zhou Y-H, Torian U, et al. Mutations within potential glycosylation sites in the capsid protein of hepatitis $\mathrm{E}$ virus prevent the formation of infectious virus particles. J Virol 2008;82:1185-1194.

26. Trémeaux P, Lhomme S, Chapuy-Regaud S, et al. Performance of an antigen assay for diagnosing acute hepatitis E virus genotype 3 infection. J. Clin. Virol. 2016;79:1-5.

27. Zhao C, Geng Y, Harrison TJ, et al. Evaluation of an antigen-capture EIA for the diagnosis of hepatitis E virus infection. Journal of Viral Hepatitis 2015;22:957-963.

28. Behrendt P, Bremer B, Todt D, et al. Hepatitis E Virus (HEV) ORF2 Antigen Levels Differentiate Between Acute and Chronic HEV Infection. Journal of Infectious Diseases 2016;214:361-368.

29. Geng Y, Zhao C, Huang W, et al. Detection and assessment of infectivity of hepatitis E virus in urine. Journal of Hepatology 2016;64:37-43.

Author names in bold designate shared co-first authorship. 


\section{ACKNOWLEDGEMENTS}

2

1 We thank Sandrine Belouzard, Karin Seron and Sophana Ung for their technical contribution. We $\frac{3}{4}$ thank Suzanne U. Emerson (NIH, USA) and Shoshana Levy (Stanford University, USA) for providing 5 us with reagents. We thank Lydia Linna for proofreading the manuscript.
6

8

9

10

11

12

13

14

15

16

17

18

19

20

21

22

23

24

25

26

27

28

29

30

31

32

33

34

35

36

37

38

39

40

41

42

43

44

45

46

47

48

49

50

51

52

53

54

55

56

57

58

59

60

61

62

63

64

65 


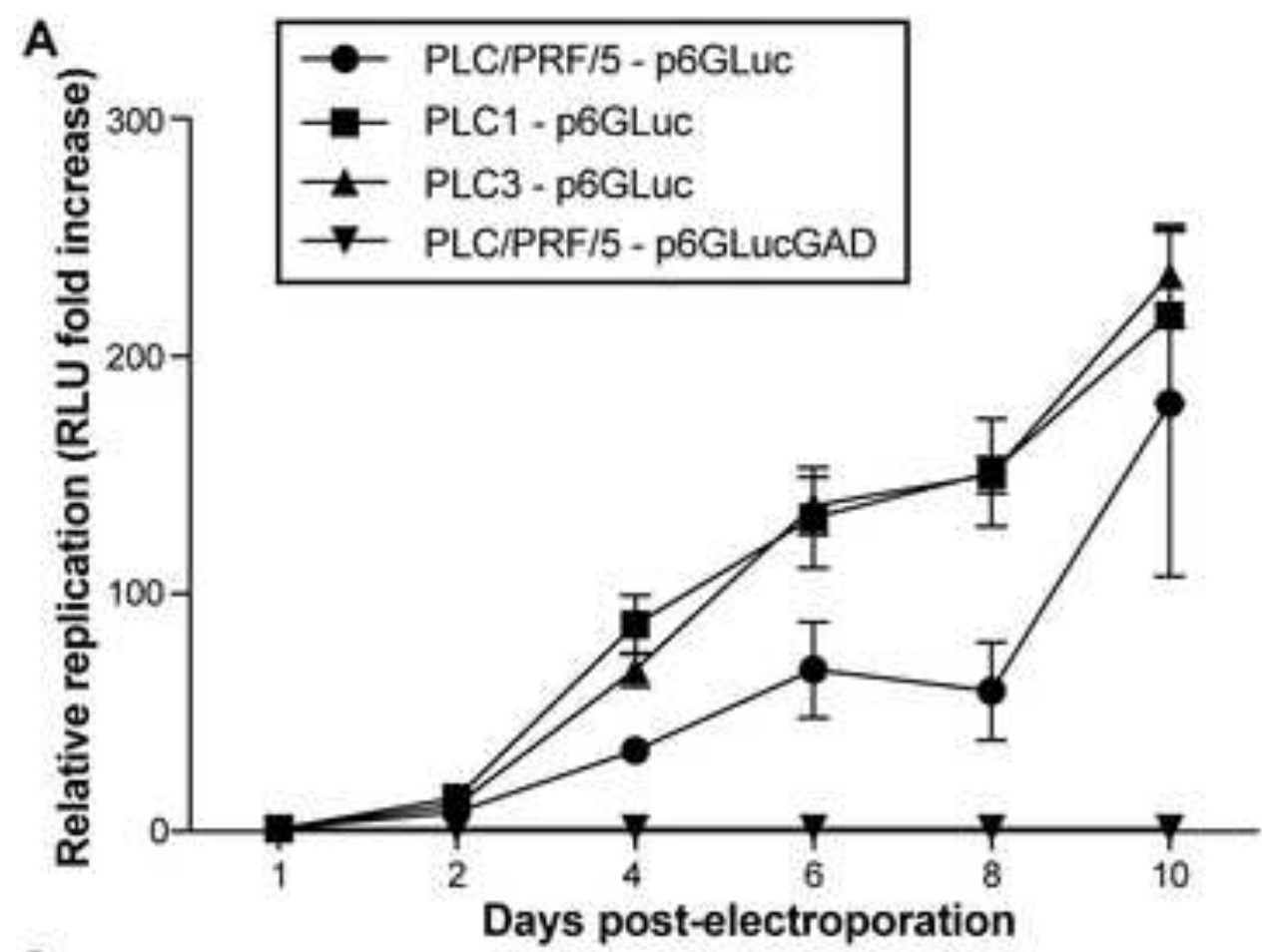

C

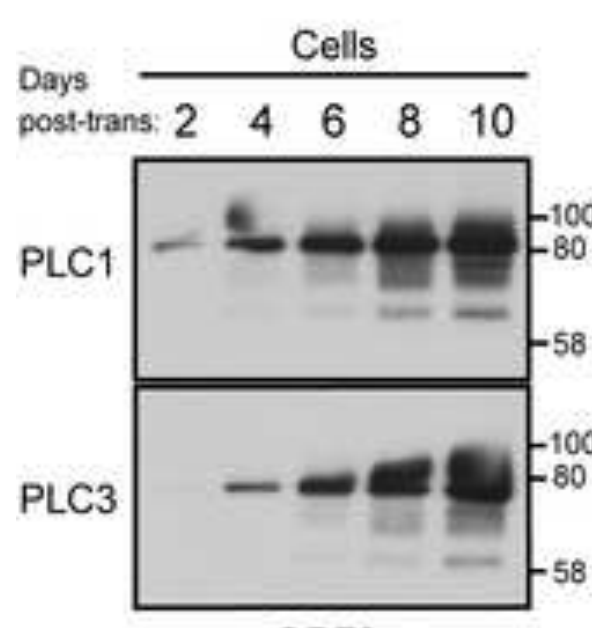

ORF2

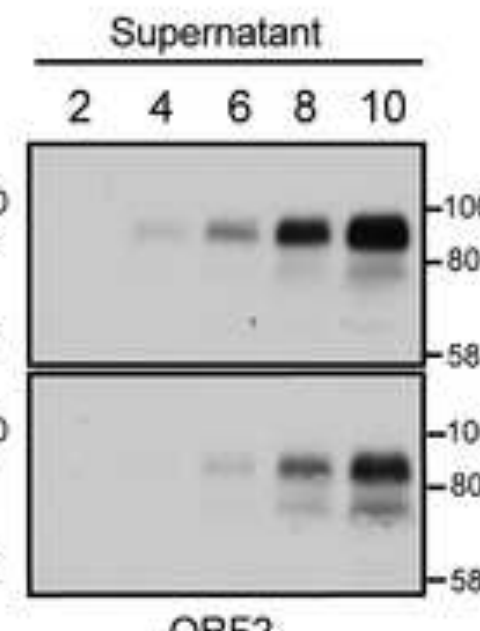

ORF2

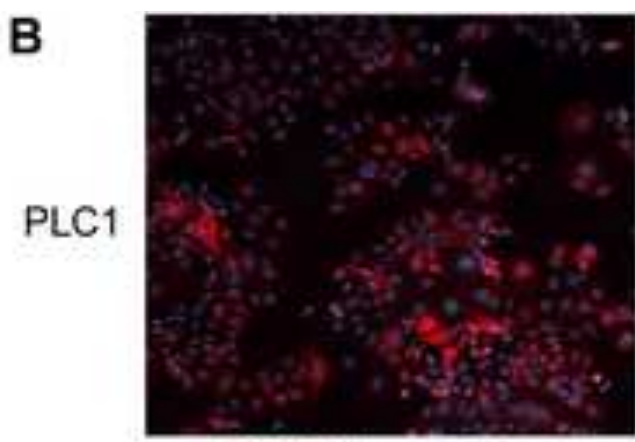

ORF2 / nuclei
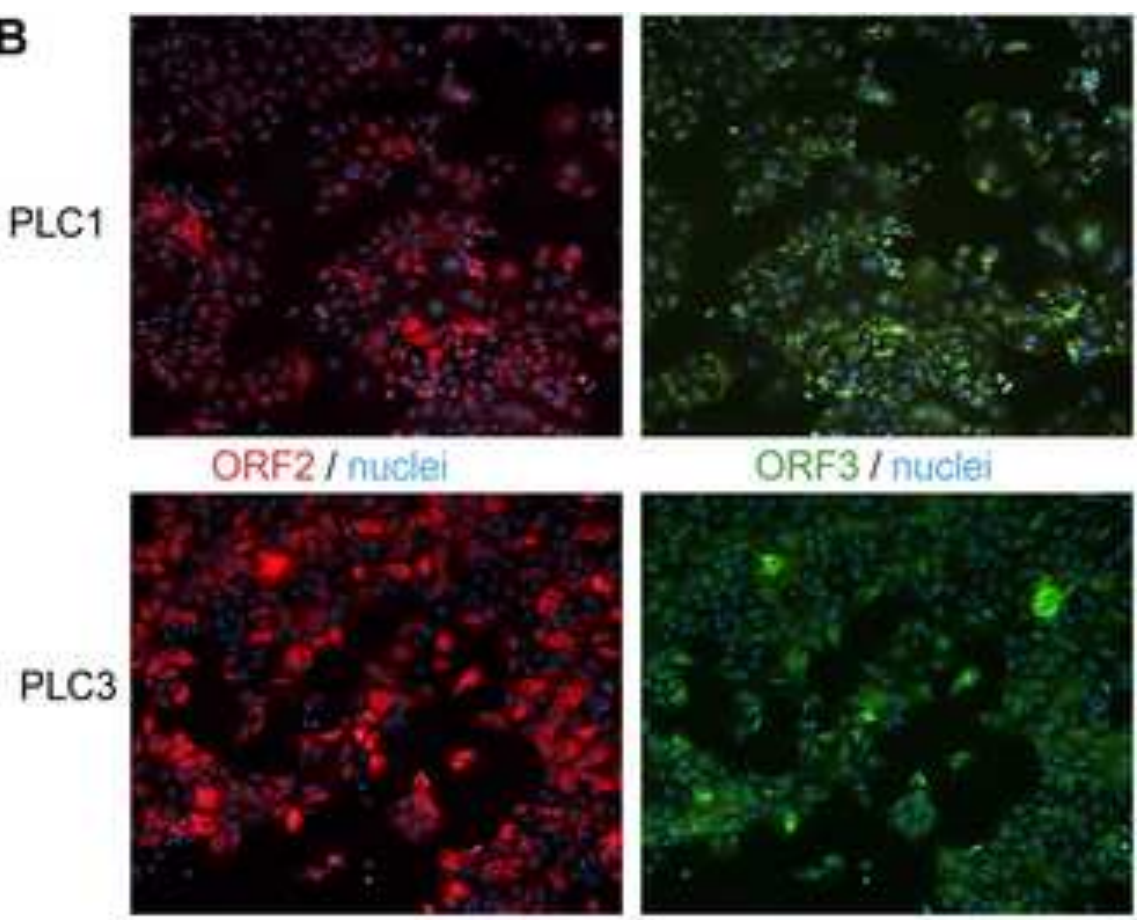

ORF3 / nuclei

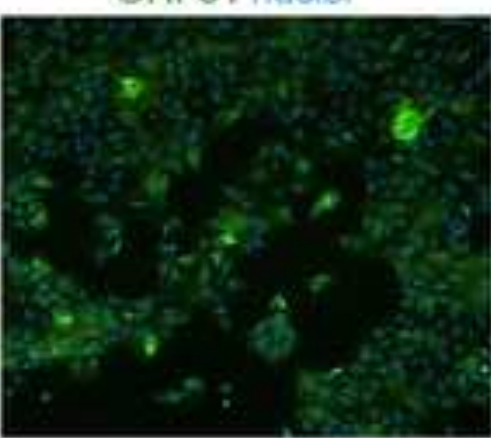

D PLC1 $\quad$ PLC3
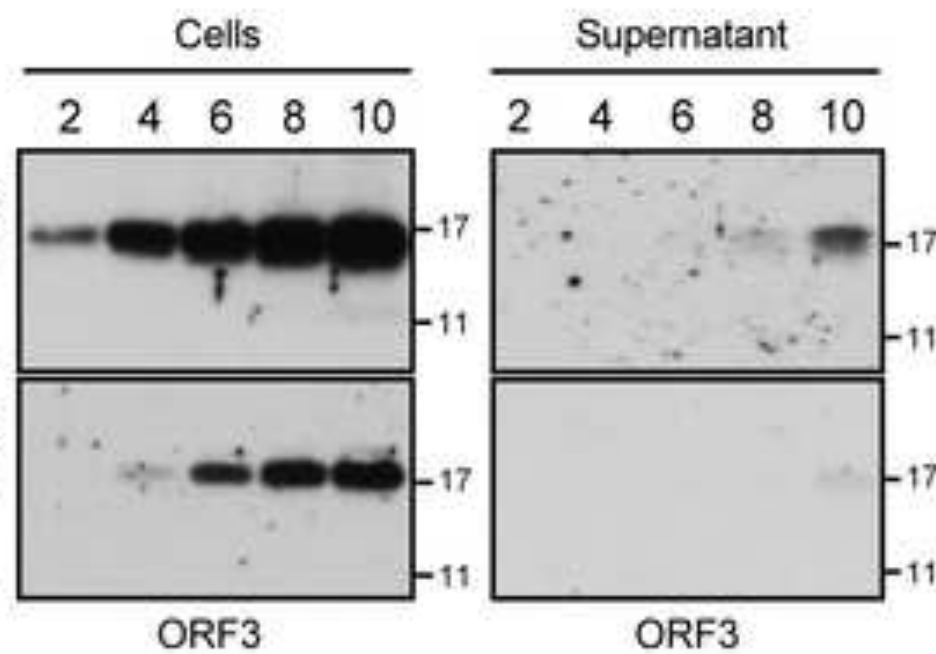
A Fractions \#

\section{A} Fractions 4

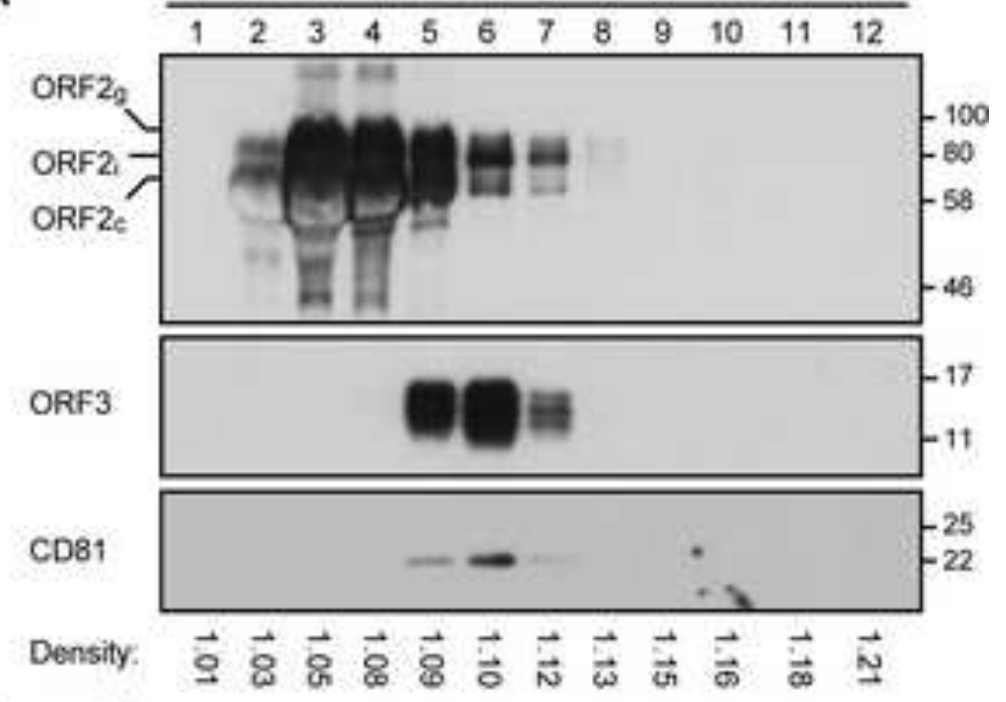

B

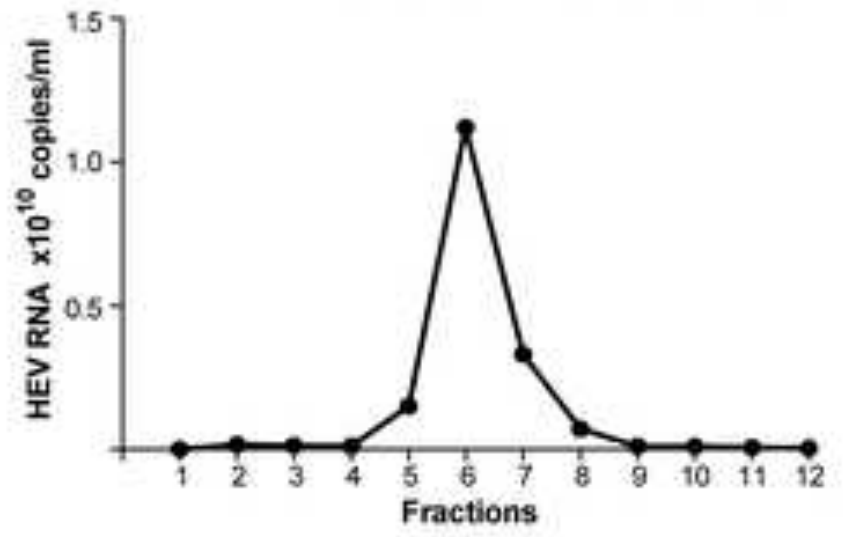

C

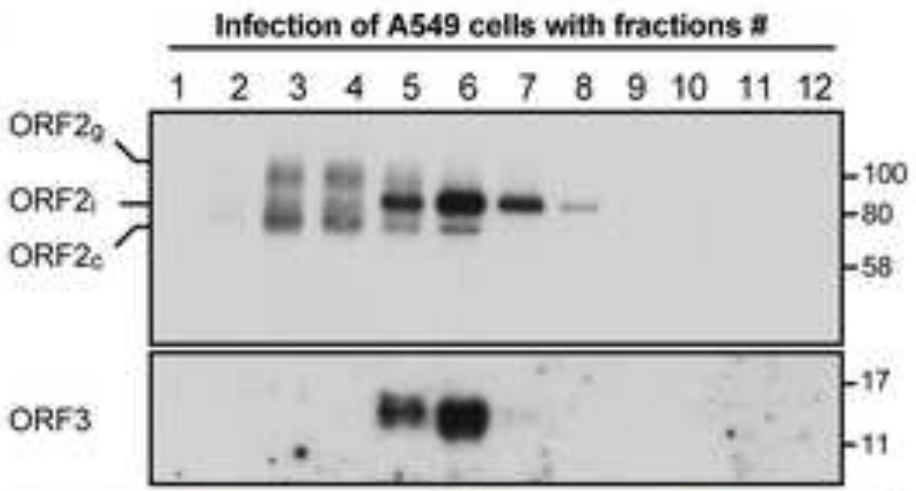

D

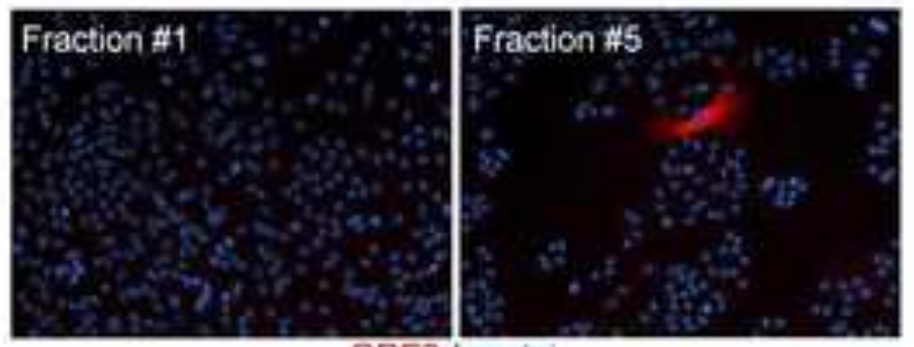

ORF2/ nucle

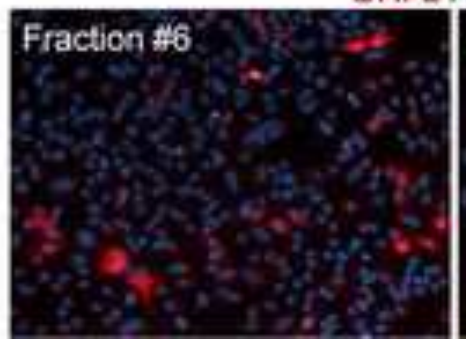

Fraction \#7

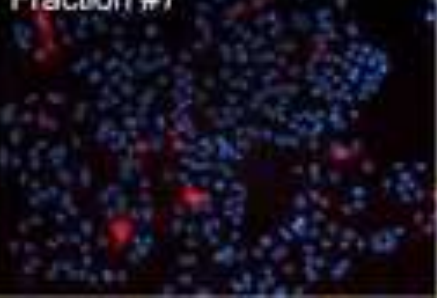


A
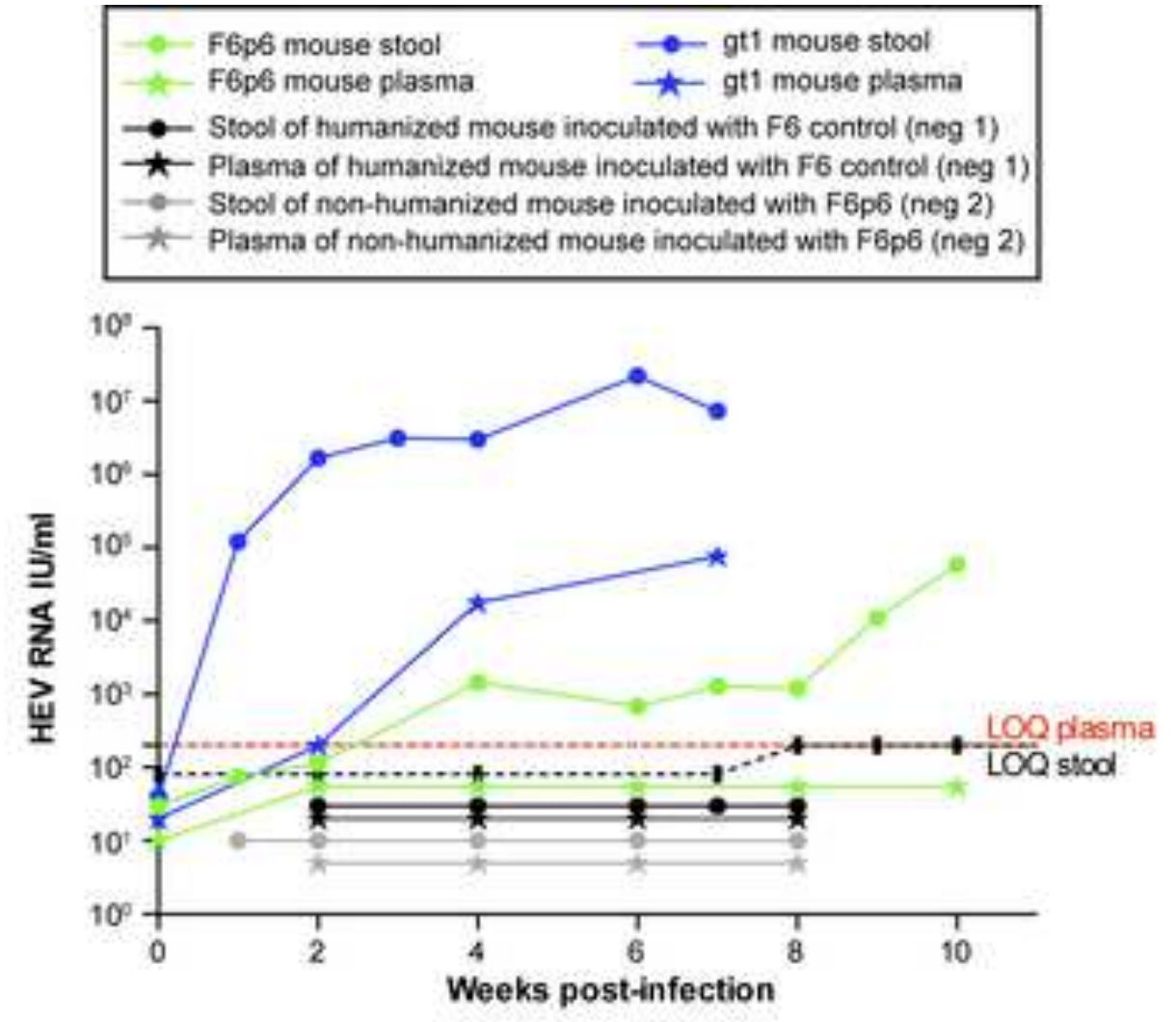

B

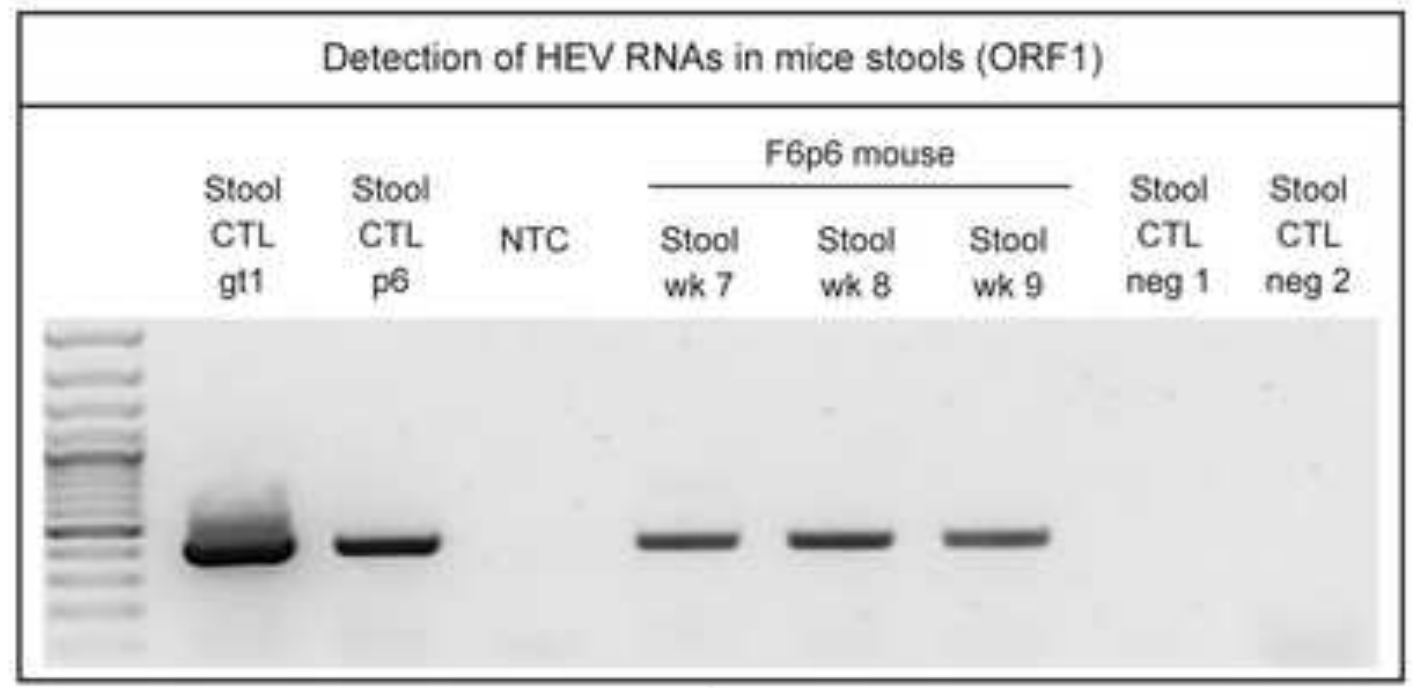

C

D

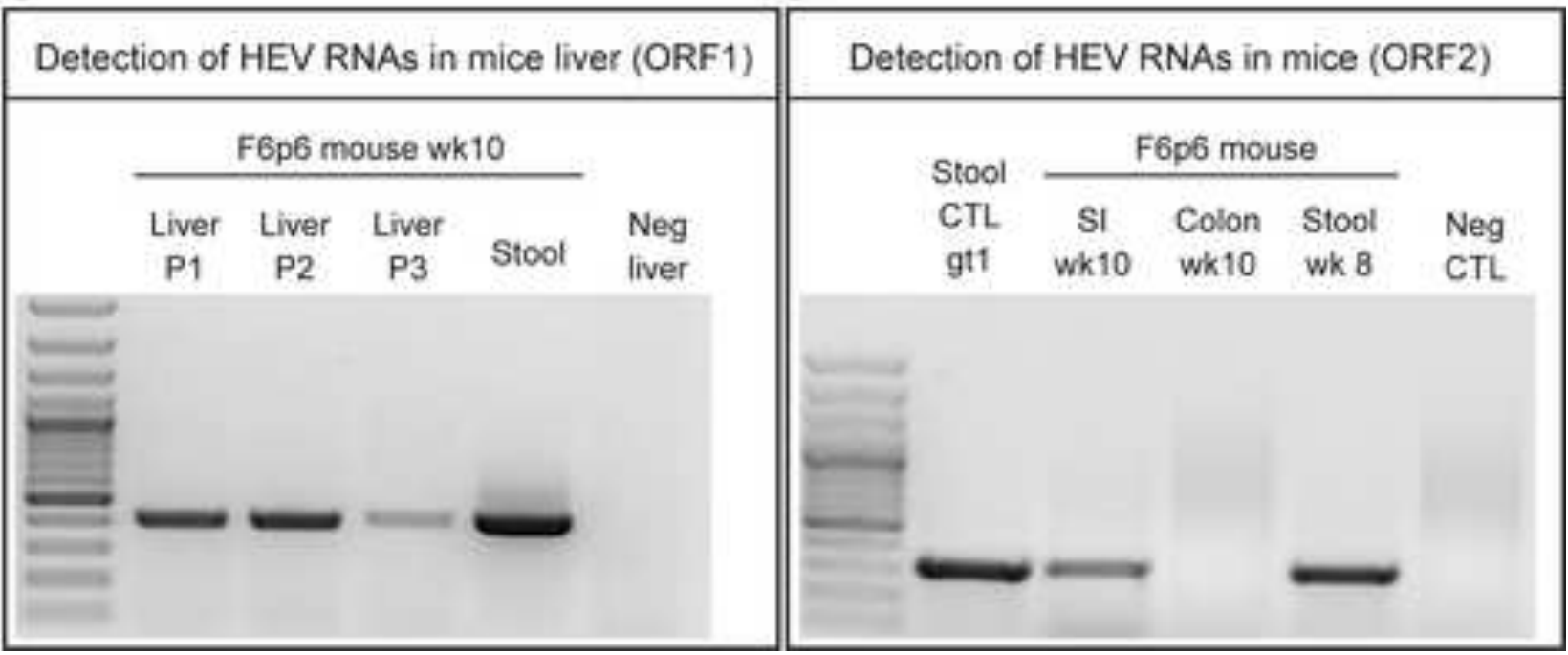




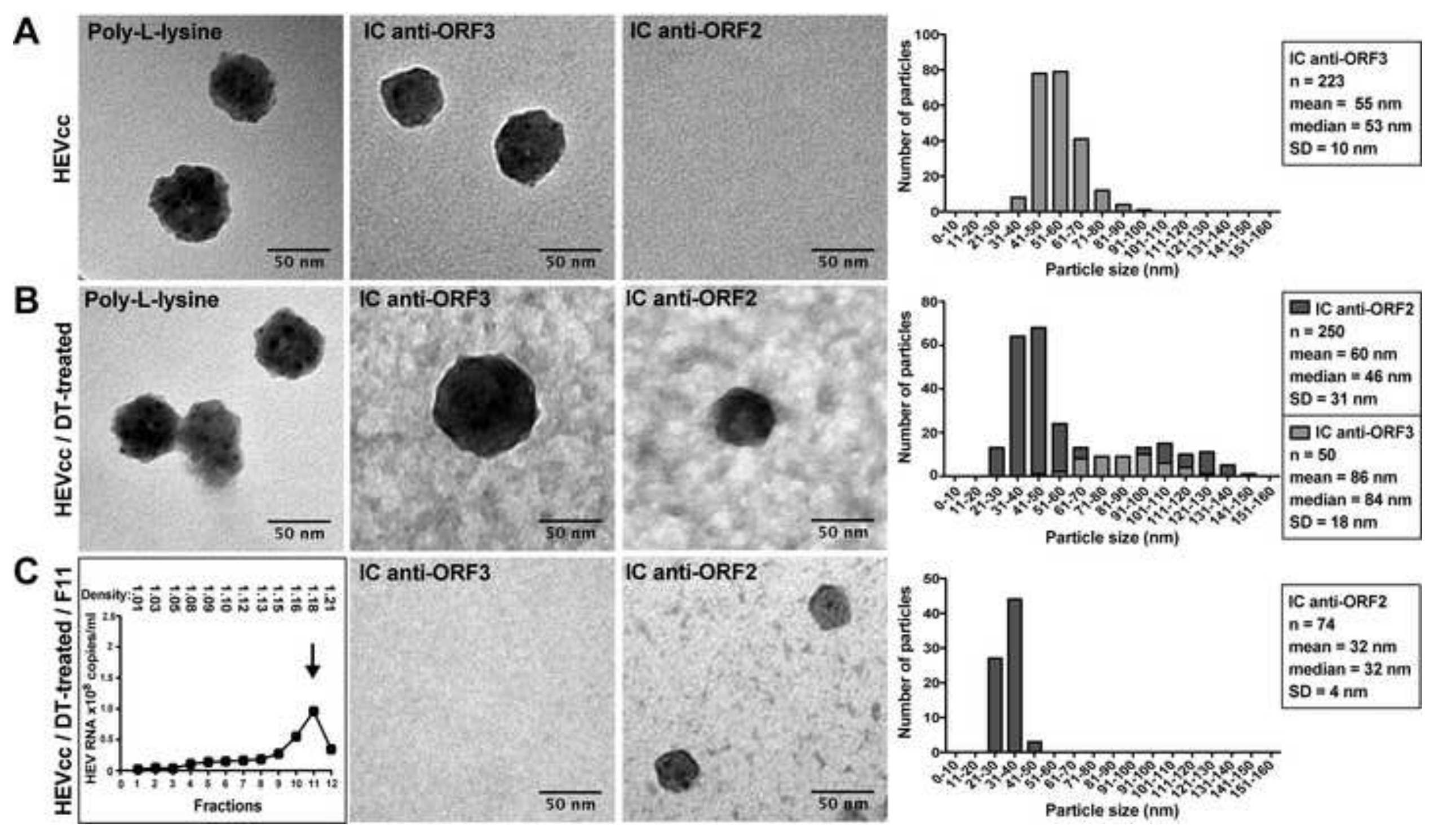



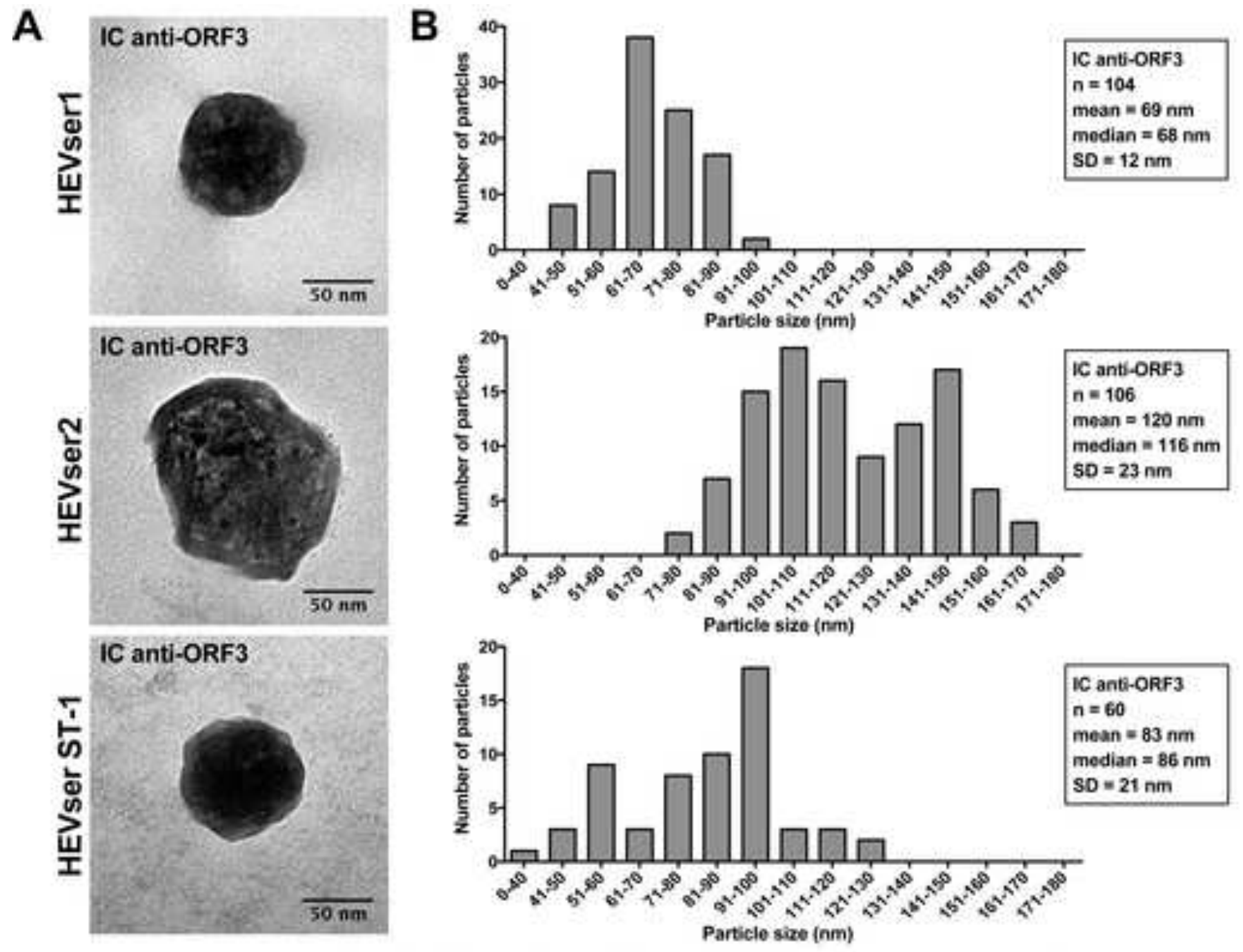

IC anti-ORF3 $n=104$ mean $=69 \mathrm{~nm}$ median $=68 \mathrm{~nm}$ $S O=12 \mathrm{~nm}$
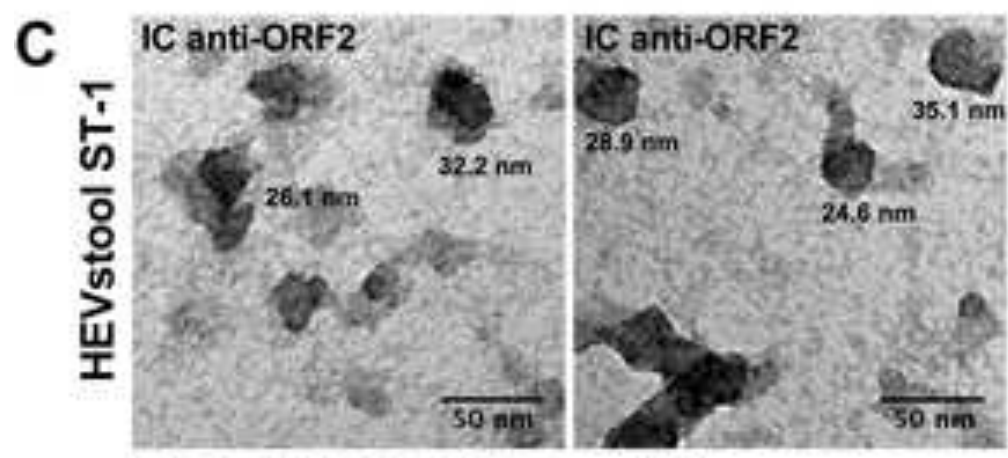

IC ant-ORF2
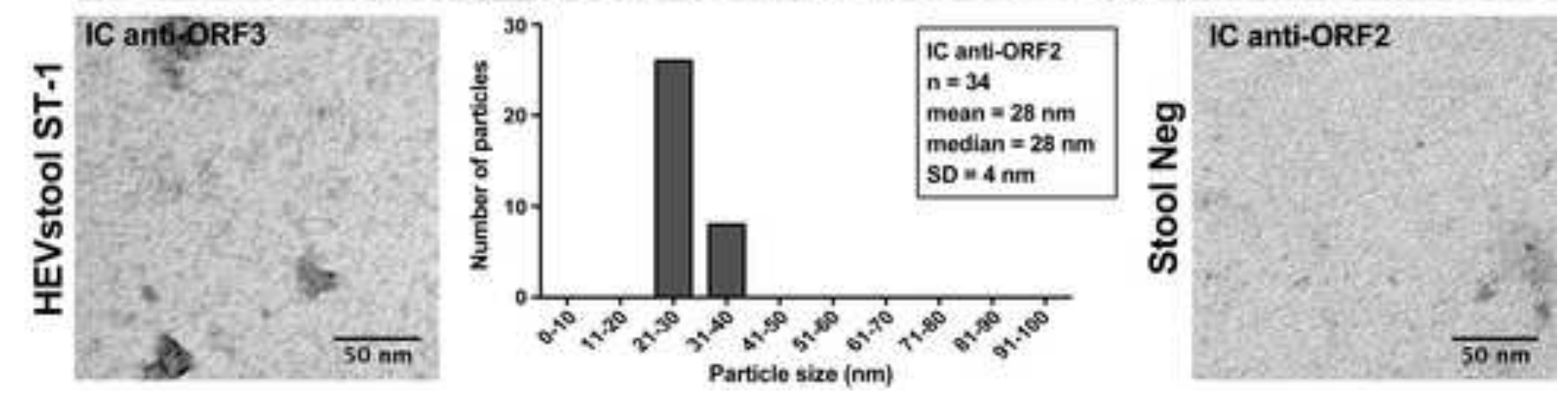

IC anti-ORF3 $n=60$ mean $=83 \mathrm{~nm}$ median $=86 \mathrm{~nm}$ $S D=21 \mathrm{~nm}$
C anti-ORF3 $=106$

= $120 \mathrm{~nm}$ median $=116 \mathrm{~nm}$

$\mathrm{D}=23 \mathrm{~nm}$

\section{Figure 5.}

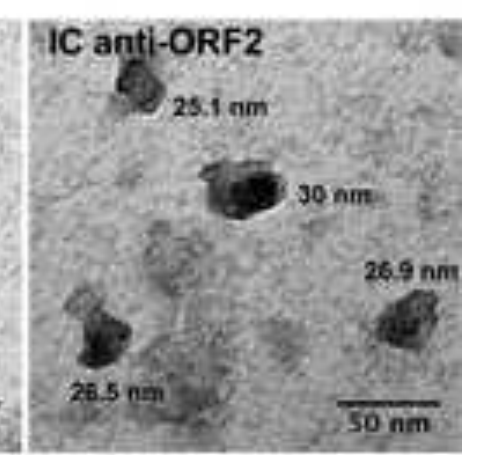


A

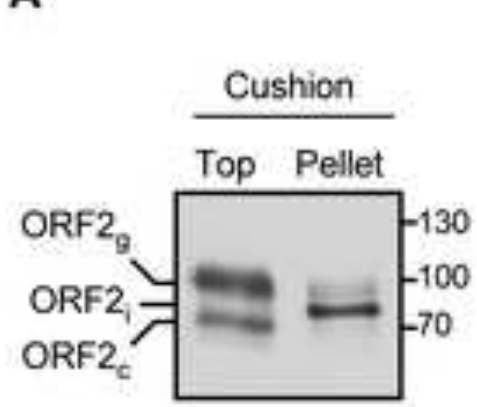

B

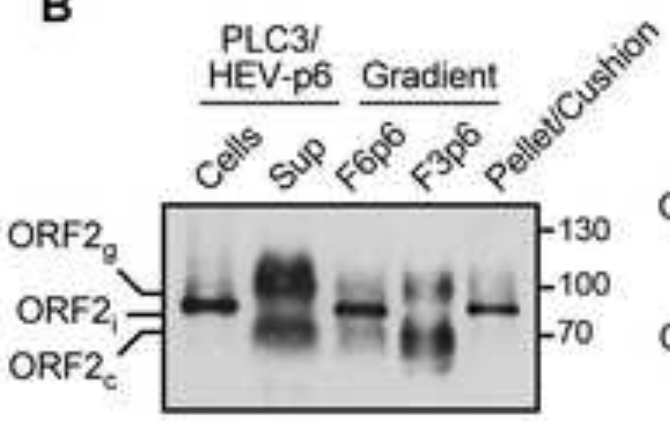

D

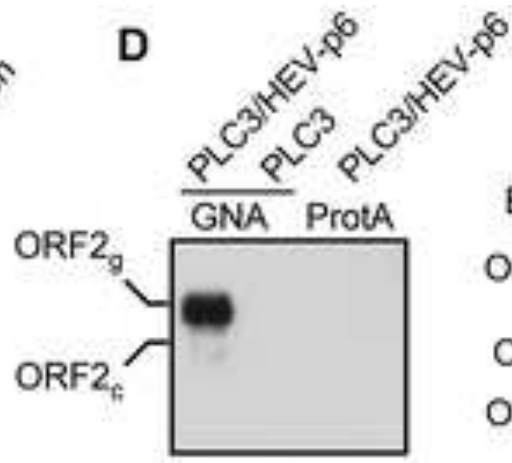

E

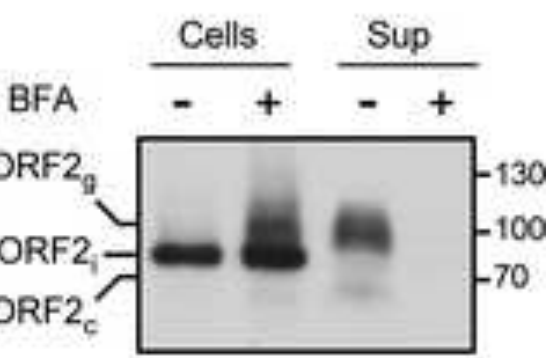

C

Cells. Supernatant HEV Particles

\begin{tabular}{|c|c|c|c|c|c|c|c|c|c|c|c|c|c|c|c|}
\hline EndoH & - & + & - & - & - & - & - & - & - & + & - & - & - & - & - \\
\hline NGaseF & - & - & + & - & - & - & + & - & - & & + & - & - & - & + \\
\hline O-Gly & - & - & - & + & - & + & + & 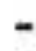 & - & - & - & + & - & + & + \\
\hline Neur: & - & - & - & - & + & + & + & - & - & - & - & - & + & + & + \\
\hline
\end{tabular}

\begin{tabular}{|c|c|c|c|c|c|c|c|}
\hline \multicolumn{8}{|c|}{ HEV Particles } \\
\hline - & + & - & - & - & - & - & - \\
\hline- & - & + & - & - & - & + & - \\
\hline - & - & - & + & - & + & + & - \\
\hline - & - & - & - & + & + & + & \\
\hline
\end{tabular}

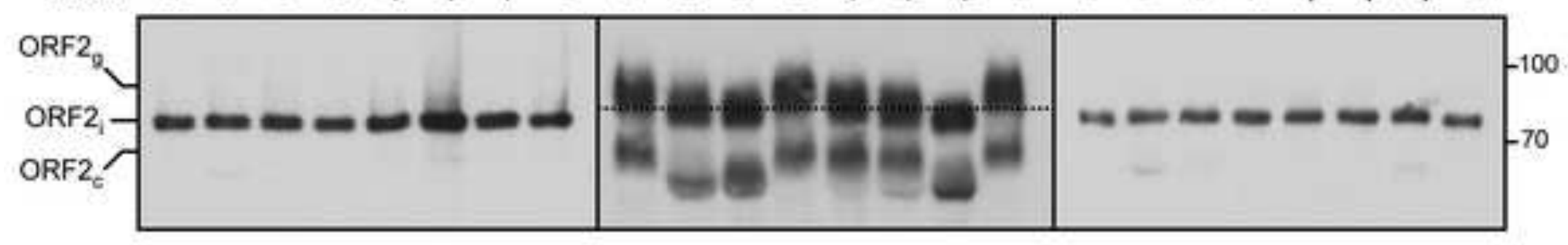

F

\begin{abstract}
1 MCPRVVLLLF. FVELPMLPAP.PAGQPSGRRR GRRSGGAGGG FWGDRVDSQP so ST FALPYIHPTN PFAADIVSQS GAGTRPRQPP RPLGSAWRDQ SQRPSAAPRR 100 101 RSAPAGAAPL TAVSPAPDTA PVPDVDSRGA ILRRQY NLST SPLTSSVASG 150 151 TNLVLYAAPL NPLLPLQDGT NTHIMATEAS NYAQYRVVRA TIRYRPLVPN 200 201 AVGGYAISIS FWPQTTTTPT SVDMNSITST DVRILVQPGI ASELVIPSER 250 25: LHYRNQGWRS VETTGVAEEE ATSGLVMLCI HGSPVNSYTN TPYTGALGLL 300 301 DFALELEFRN LTPGNTNTRV SRYTSTARHR LRRGADGTAE LTTTAATRFM 350 351 KDLHFTGTNG VGEVGRGIAL TLFNLADTLL GGLPTELISS AGGQLFYSRP 400 401 VVSANGEPTV KLYTSVENAQ QDKGITIPHD IDLGDSRVVI QDYDNQHEQD 45 451 RPTPSPAPSR PFSVLRANDV LWLSLTAAEY DQATYGSSTN PMYVSDTVTF 500 501 VNVATGAQAV ARSLDWSKVT LDGRPLTTIQ QYSKTFYVLP LRGKLSFWEA 550 S6I GTTRAGYPYN VNTTASDQIL IENAAGHRVA ISTYTTSLGA GPASISAVGV 600 601 LAPHSALAVL EDTVDYPARA HTFDDFCPEC RTLGLQGCAF QSTIAELQRL GSO ES1 KTEVGKTRES 660
\end{abstract}


A

Patient sera:

HEV neg

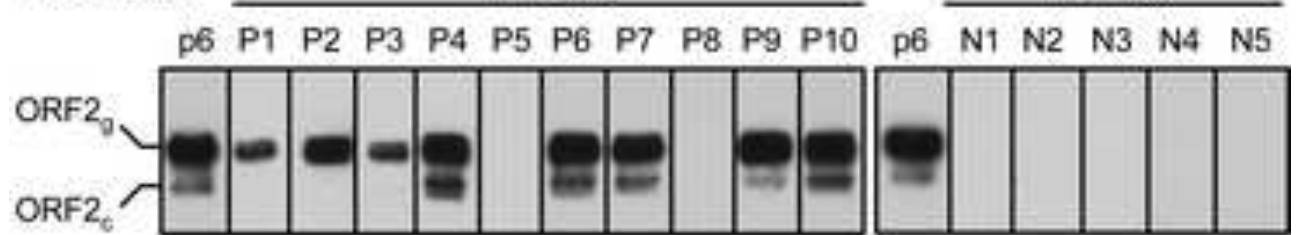

GNA pull-down + WB ORF2

B

Fractions
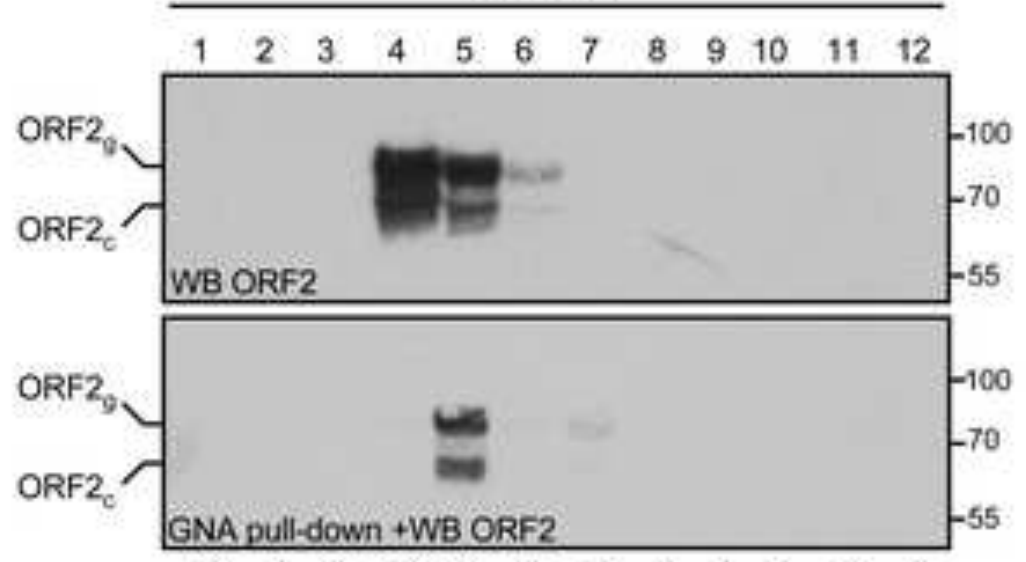

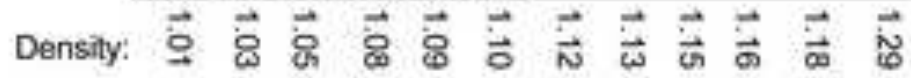

C

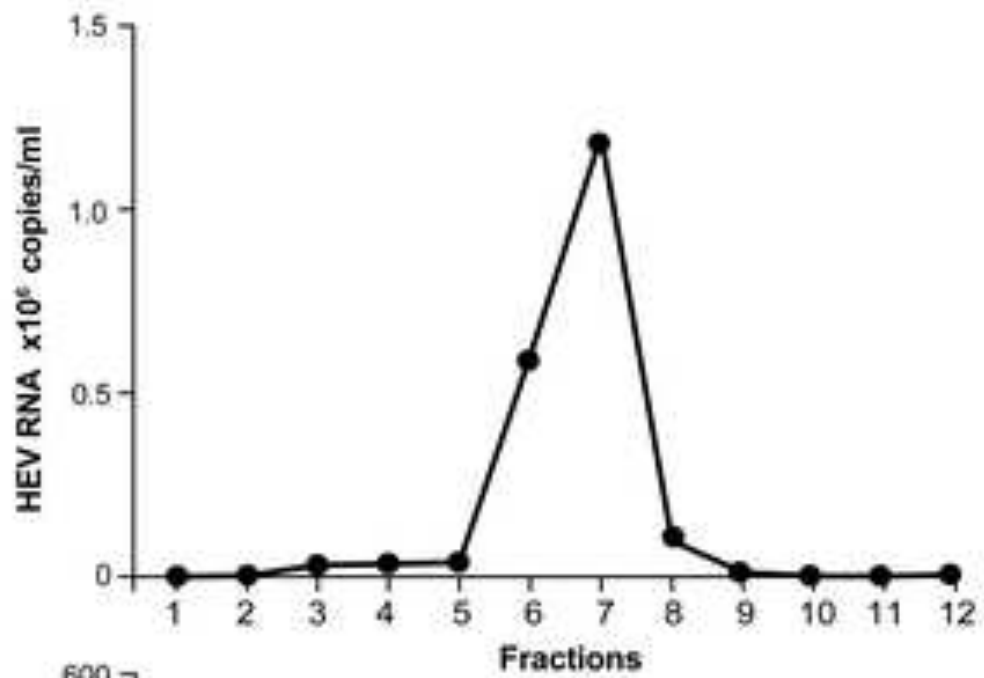

D

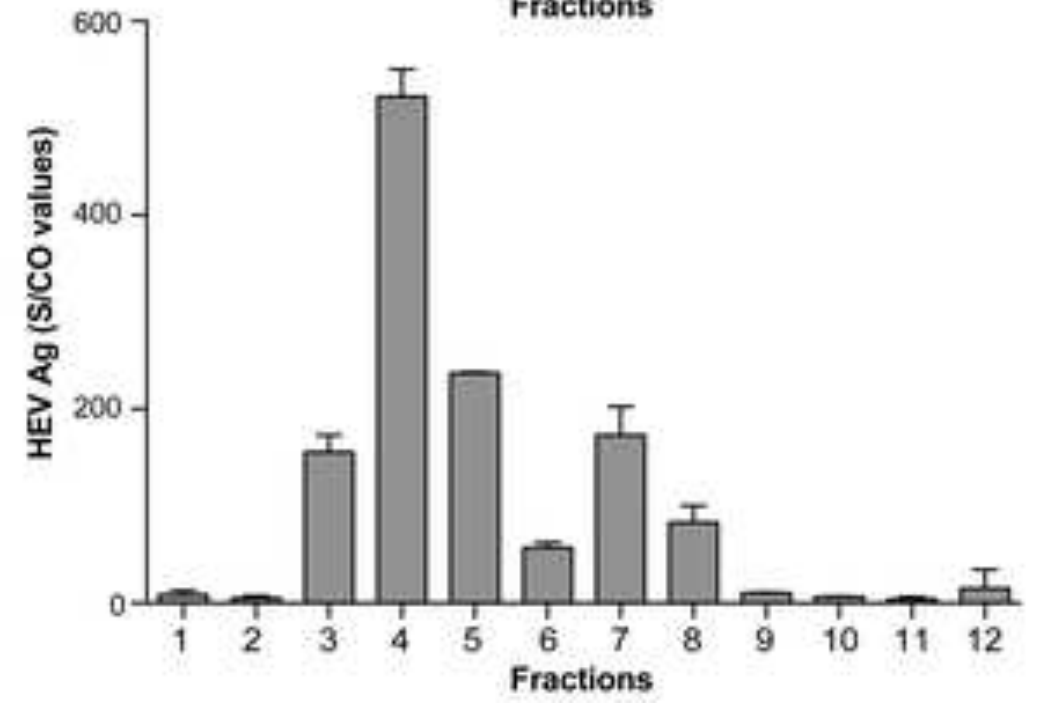


4 Hepatitis E Virus Lifecycle and Identification of 3 Forms of the ORF2 5 Capsid Protein

6

7

8

Claire Montpellier ${ }^{\mathrm{a}, \#}$, Czeslaw Wychowski ${ }^{\mathrm{a}, \#}$, Ibrahim M. Sayed ${ }^{\mathrm{b}, \mathrm{c}}$, Jean-Christophe Meunier ${ }^{\mathrm{d}}$, Jean-Michel Saliou ${ }^{\mathrm{a}}$, Maliki Ankavay ${ }^{\mathrm{a}}$, Anne Bull ${ }^{\mathrm{d}}$, André Pillez ${ }^{\mathrm{a}}$, Florence Abravanel ${ }^{\mathrm{e}}$, François Helle ${ }^{\mathrm{f}}$, Etienne Brochot ${ }^{\mathrm{f}}$, Hervé Drobecq ${ }^{\mathrm{g}}$, Rayan Farhat ${ }^{\mathrm{a}}$, Cécile-Marie AliouatDenis $^{\text {a }}$, Juliano G. Haddad ${ }^{\mathrm{a}}$, Jacques Izopet ${ }^{\mathrm{e}}$, Philip Meuleman ${ }^{\mathrm{b}}$, Anne Goffard ${ }^{\mathrm{a}}$, Jean Dubuisson $^{\mathrm{a}}$, Laurence Cocquerel ${ }^{\mathrm{a}}$

a University of Lille, CNRS, INSERM, CHU Lille, Pasteur Institute of Lille, U1019UMR8204-CIIL- Center for Infection and Immunity of Lille, F-59000 Lille, France

${ }^{\mathrm{b}}$ Laboratory of Liver Infectious Diseases, Department of Clinical Chemistry, Microbiology and Immunology, Ghent University, Ghent, Belgium.

${ }^{\mathrm{c}}$ Microbiology and Immunology Department, Faculty of Medicine, Assiut University, Assiut, Egypt.

${ }^{\mathrm{d}}$ Inserm-U966, University F. Rabelais, F-37032 Tours, France.

e CHU Toulouse, Hôpital Purpan, Laboratoire de virologie, National Reference Center for Hepatitis E, F-31300, France.

${ }^{\mathrm{f}}$ EA4294, Laboratoire de Virologie, Centre Universitaire de Recherche en Santé, Centre Hospitalier Universitaire et Université de Picardie Jules Verne, Amiens, France

g Univ. Lille, CNRS, Institut Pasteur de Lille, UMR 8161-M3T-Mechanisms of Tumorigenesis and Target Therapies, Lille, France. 
3 Antibodies. Two rabbit anti-ORF3 polyclonal antibodies were used in this study, one provided by S.U Emerson (NIH, USA) ${ }^{1}$ and the other from Bioss Antibodies. Mouse antiHEV ORF2 monoclonal antibodies (MAbs) (1E6, antibody registry \#AB-827236 and 4B2 \#AB-571018) were from Millipore. Anti-CD81 MAb (5A6) was kindly provided by S. Levy. Secondary antibodies were from Jackson ImmunoResearch.

Luciferase assay. Cells were electroporated with HEV-p6GLuc RNA or HEV-p6GlucGAD RNA. One day post-electroporation, the medium was collected (D1, Day 1) and replaced with DMEM/M199/Additives. Every two days (D2, D4, D6, D8, D10) during 10 days, a sample of medium was collected from each well. GLuc activities were determined with the Renilla luciferase assay system (Promega) and using a Tristar LB941 luminometer (Berthold). Values were normalized relative to those at D1.

Infectious titers. A549 cells were infected with dilutions $\left(10^{-1}\right.$ to $\left.10^{-7}\right)$ of infectious supernatants or fractions of iodixanol gradient for $6 \mathrm{~h}$ at $37^{\circ} \mathrm{C}$. The inocula were removed and replaced by fresh complete medium. Five days post-infection, cells were fixed and processed for indirect immunofluorescence. Cells labeled with anti-ORF2 antibody 1E6 were counted as infected cells. The number of infected cells was determined for each dilution and used to define the infectious titer in focus forming unit (ffu) $/ \mathrm{ml}$.

Indirect immunofluorescence. Cells were fixed with methanol/acetone (1v:1v) $20 \mathrm{~min}$ at $20^{\circ} \mathrm{C}$ and then processed for immunofluorescence detection as previously described ${ }^{2}$. Mouse anti-HEV ORF2 MAb (1E6/IgG2b) rabbit anti-ORF3 polyclonal antibody (S.U. Emerson) were used at a 1/800 and 1/2000 dilution, respectively. Image acquisition was carried out using an Axiophot 2 microscope (Zeiss).

RNA extraction and quantification. Samples were treated with RNase A during $30 \mathrm{~min}$ at room temperature before nucleic acid extraction with the QIAamp Viral RNA Mini Kit (Qiagen). HEV RNA levels were quantified by RT-qPCR (real-time-quantitative polymerase chain reaction) assay by using primers and probes targeting a conserved 70 base pair region in the ORF2/ORF3 overlap, as previously described ${ }^{3}$. 
1 Detection of HEV ORF1 in mouse liver and stool samples. RNA extracted from mouse

2 stool and mouse liver was converted into cDNA using Superscript IV enzyme (Life

3 Technologies, Belgium) with specific primers ${ }^{4}$ according to the manufacturer's instructions.

$4 \quad 10 \mu \mathrm{l}$ of purified cDNA was used in first PCR run using ORF1 primers ${ }^{4}$ and Dream Taq DNA polymerase (Thermo Fischer Scientific, Belgium) according to the following conditions: initial denaturation at $95^{\circ} \mathrm{C}$ for 2 minutes, followed by 40 cycles of amplification (denaturation at $95^{\circ} \mathrm{C}$ for $30 \mathrm{sec}$, annealing at $55^{\circ} \mathrm{C}$ for $30 \mathrm{Sec}$, extension at $72^{\circ} \mathrm{C}$ for $1 \mathrm{~min}$ ) and final extension at $72^{\circ} \mathrm{C}$ for $5 \mathrm{~min} .10 \mu \mathrm{l}$ of the first PCR product was used for the second PCR run using Dream Taq DNA polymerase according to the following conditions: initial denaturation at $95^{\circ} \mathrm{C}$ for 2 minutes, followed by 20 cycles of amplification (denaturation at $95^{\circ} \mathrm{C}$ for $30 \mathrm{sec}$, annealing at $55^{\circ} \mathrm{C}$ for $30 \mathrm{Sec}$, extension at $72^{\circ} \mathrm{C}$ for $30 \mathrm{sec}$ ) and final extension at $72^{\circ} \mathrm{C}$ for $5 \mathrm{~min}$; the expected band size was $415 \mathrm{bp}$.

Detection of HEV ORF2 in mouse samples. First, a one step RT-PCR was performed on $10 \mu 1$ of extracted RNA using the LightCycler Multiplex RNA Virus Master (Roche, Belgium) in combination with the primers RT_5'-CCCTTRTCYTGCTGMGCATTCTC-3', Fow_5'AATTATGCYCAGTAYCGRGTTG-3' and Rev_5'-CCCTTRTCYTGCTGMGCATTCTC$3^{\prime}$ ' according to the following conditions: RT step at $50^{\circ} \mathrm{C}$ for $10 \mathrm{~min}$, initial denaturation at $95^{\circ} \mathrm{C}$ for 1 minute, followed by 40 cycles of amplification (denaturation at $95^{\circ} \mathrm{C}$ for $5 \mathrm{sec}$, annealing at $47^{\circ} \mathrm{C}$ for $45 \mathrm{sec}$, and extension at $60^{\circ} \mathrm{C}$ for $45 \mathrm{sec}$ ) and final extension at $60^{\circ} \mathrm{C}$ for 7 minutes. Nested PCR reaction was done on $10 \mu 1$ of the first-round PCR product using Taq DNA polymerase (New England Biolabs, MA, USA) and the primers Fow_5'GTWATGCTYTGCATWCATGGCT-3' and Rev_5'-AGCCGACGAAATCAATTCTGTC$3^{\prime}$ according to the following conditions: initial denaturation at $95^{\circ} \mathrm{C}$ for $30 \mathrm{sec}$, followed by 30 cycles of amplification (denaturation at $95^{\circ} \mathrm{C}$ for $30 \mathrm{sec}$, annealing at $47^{\circ} \mathrm{C}$ for $45 \mathrm{sec}$, and extension at $68^{\circ} \mathrm{C}$ for $40 \mathrm{sec}$ ) and final extension at $68^{\circ} \mathrm{C}$ for 7 minutes. The expected size of the nested PCR product was 348bp.

Particle size distribution. Series of electron micrographs (numbers as indicated) were acquired at random from anti-ORF2 or anti-ORF3 IC TEM grids. The images were then analyzed with Image-J software to determine the particle size distribution. 
1 supernatant of PLC3/HEV-p6 cells were immunoprecipitated with the 4B2 anti-ORF2

2 antibody (Millipore). Proteins were resolved by SDS-PAGE. Colloïdal blue stained bands

3 corresponding to ORF2i, ORF2g and ORF2c proteins in WB were cut into two slices for in-

4 gel digestion with trypsin or AspN. NanoLC-MSMS analyses of the protein digests were

5 performed on a UltiMate-3000 RSLCnano System coupled to a Q-Exactive instrument

6 (Thermo Fisher Scientific), as previously described ${ }^{5}$. For N-terminus identification, viral

7 particles or immunoprecipitated $\mathrm{ORF} 2 \mathrm{~g} / \mathrm{ORF} 2 \mathrm{c}$ proteins were denaturated for $20 \mathrm{~min}$ at $80^{\circ} \mathrm{C}$

8 then incubated for $3 \mathrm{~h}$ at RT in 50mM NaPO4, pH8.2, 10\% CH3CN, 1\% SDS, 2mM TMPP-

9 Ac-OSu. Following trypsin digestion, mass spectrometry analyses were performed as above

10 and identified TMPP-labeled N-terminal peptides were validated as previously described ${ }^{6}$.

11 Collected raw data were processed and converted into *.mgf peak list format with Proteome

12 Discoverer 1.4 (Thermo Fisher Scientific). MS/MS data were interpreted using search engine

13 Mascot (version 2.4.0, Matrix Science) with a tolerance on mass measurement of 0.2 Da for

14 precursor and 0.2 Da for fragment ions, against a composite target-decoy database (40584

15 total entries) built with Swissprot Homo sapiens database (Tax ID=9606, 20 May 2016, 20209

16 entries) fused with the sequences of ORF2 (H9E9C9_HEV) and a list of classical

17 contaminants (119 entries). Carbamidomethylation of cysteine residues, oxidation of

18 methionine residues, protein $\mathrm{N}$-terminal acetylation and propionamidation of cysteine

19 residues were searched as variable modifications. Up to one trypsin or three Asp-N missed

20 cleavages were allowed. Semi-specific cleavage was also authorized. Peptides were filtered

21 out according to the cutoff ion score $>25$ and a minimal size of 7 amino acid residues. 
2

3 Supplementary table 1: HEV RNA levels and infectious titers of PLC1/HEV-p6 and 4 PLC3/HEV-p6 cell supernatants.

5

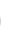

Supplementary table 2 : Features of HEV patient sera used in GNA pull-down

\begin{tabular}{|c|c|c|c|c|c|}
\hline Patients & Genotype & Serum titer $^{\mathrm{a}}$ & $\begin{array}{c}\text { Amount used in } \\
\text { GNA pull-down }^{\mathrm{b}}\end{array}$ & Ag levels $^{\mathrm{c}}$ & ORF2 proteins $^{\mathrm{d}}$ \\
\hline P1 & 3c & $1.3 \times 10^{8}$ & $6.5 \times 10^{6}$ & 17.4 & ORF2g \\
\hline P2 & 3c & $3.7 \times 10^{7}$ & $1.8 \times 10^{6}$ & 19.4 & ORF2g \\
\hline P3 & 3c & $2.1 \times 10^{7}$ & $2.1 \times 10^{6}$ & 17.4 & ORF2g \\
\hline P4 & ND & $2.0 \times 10^{5}$ & $1.0 \times 10^{5}$ & 20.2 & ORF2g/ORF2c \\
\hline P5 & 3f & $7.0 \times 10^{5}$ & $3.5 \times 10^{5}$ & ND & - \\
\hline P6 & 3c & $1.6 \times 10^{8}$ & $1.6 \times 10^{7}$ & 19.4 & ORF2g/ORF2c \\
\hline P7 & 3c & $1.2 \times 10^{7}$ & $1.2 \times 10^{6}$ & 18.6 & ORF2g/ORF2c \\
\hline P8 & 3f & $1.2 \times 10^{5}$ & $0.6 \times 10^{5}$ & 5 & - \\
\hline P9 & 3f & $1.5 \times 10^{5}$ & $0.7 \times 10^{5}$ & 19.7 & ORF2g/ORF2c \\
\hline P10 & 3f & $1.2 \times 10^{6}$ & $0.6 \times 10^{6}$ & 18.9 & ORF2g/ORF2c \\
\hline
\end{tabular}

${ }^{a}$ in HEV RNA copies/ml

$\mathrm{b}$ in HEV RNA copies

${ }^{c}$ in S/CO values. Samples were diluted 100 times in PBS and quantified with the Wantaï HEV-Ag-ELISA kit.

d detected in GNA pull-down + WB anti-ORF2

Days post-electroporation

\begin{tabular}{|c|c|c|c|c|c|c|c|}
\hline & & 2 & 4 & 6 & 8 & 10 & Fold increase \\
\hline \multirow{2}{*}{ PLC1/HEV-p6 } & $\mathbf{R N A s}^{\mathrm{a}}$ & $8 \times 10^{6}$ & $2.4 \times 10^{7}$ & $6 \times 10^{7}$ & $7.7 \times 10^{7}$ & $1.1 \times 10^{8}$ & 14 \\
\hline & Titers $^{\mathrm{b}}$ & $2 \times 10^{2}$ & $1 \times 10^{3}$ & $2.5 \times 10^{3}$ & $5 \times 10^{3}$ & $7 \times 10^{3}$ & 35 \\
\hline \multirow{2}{*}{ PLC3/HEV-p6 } & RNAs $^{\mathrm{a}}$ & $4.2 \times 10^{6}$ & $5 \times 10^{6}$ & $1.2 \times 10^{7}$ & $2 \times 10^{7}$ & $3.3 \times 10^{7}$ & 8 \\
\hline & Titers $^{b}$ & $<10$ & $1.7 \times 10^{2}$ & $5 \times 10^{2}$ & $9 \times 10^{2}$ & $1.5 \times 10^{3}$ & $>150$ \\
\hline
\end{tabular}

copies $/ \mathrm{m}$

$\mathrm{b}$ ffu $/ \mathrm{ml}$ . 
SUPPLEMENTARY FIGURE LEGENDS

3 Supplementary figure 1: Sofosbuvir inhibits ORF2 expression. HEV-p6 electroporated

$4 \quad$ PLC3 cells were cultured in the presence of Sofosbuvir (SFV) at the indicated concentrations. At 10 days post-electroporation, ORF2 expression was analyzed by immunofluorescence (A) and western-blotting (B) by using anti-ORF2 antibody 1E6. Tubulin was used as a loading control.

Supplementary figure 2: Characterization of the different ORF2 products. Viral particles purified on iodixanol cushion and ORF2g/ORF2c proteins immunoprecipitated with an antiORF2 antibody (4B2) were resolved by SDS-PAGE. Colloïdal blue (CB) staining and WB are shown. The arrow indicates ORF2i (A), ORF2g (B) and ORF2c (C). The asterisk indicates human albumin. $\mathrm{H}$ and $\mathrm{L}$ indicate the heavy and light chains of immunoglobulins used in IP. ORF2 forms were digested in-gel with trypsin or AspN and analyzed by nanoLC-MS/MS. Peptide covering is highlighted in grey on the sequence of each ORF2 product. Dashed lines correspond to semi-trypsic and semi-AspN peptides. $\mathrm{Leu}^{14}$ and $\mathrm{Ser}^{34}$ in bold correspond to the first aa of ORF2i (A) and ORF2g (B), respectively, that were identified by semi-specific cleavage and TMPP-Ac-OSu labeling. No evidence was found for the N-terminal part of ORF2c (C).

\section{Supplementary figure 3: MS/MS spectrum of N-terminal peptides of ORF2i and ORF2g} proteins. (A-B) Semi-trypsic peptide 14-28 obtained from non-treated (A) or TMPP-Ac-Osulabeled (B) ORF2i protein. +572 corresponds to the TMPP mass increment following TMPPAc-Osu labeling. (C-D) Trypsic peptide 34-55 obtained from non-treated (C) or TMPP-AcOsu-labeled (C) ORF2g protein. (E-F) Semi-AspN peptide 34-56 obtained from non-treated (E) or TMPP-Ac-Osu-labeled (F) ORF2g protein.

Supplementary figure 4 : ORF2g/c proteins inhibit HEVcc infection. Huh-7.5 cells were inoculated with purified HEVcc (HEV-p6) in combination with either fraction 3 (F3) of iodixanol gradients prepared with a SN of PLC3/HEV-p6 cells (F3/ORF2g/c) or with F3 of iodixanol gradients prepared with a SN of non-transfected PLC3 cells (F3/CTL). Huh-7.5 cells inoculated with an iodixanol cushion prepared with a SN of non-transfected PLC3 cells are shown as Mock in the presence of F3/CTL or F3/ORF2g/c. Ten hours post-infection, 
1 were fixed and processed for indirect immunofluorescence. Cells labeled with the anti-ORF2 2 antibody 1E6 were counted as infected cells. Values were adjusted to $100 \%$ infection for cells 3 infected with HEV-p6 + F3/CTL. Results are representative of three independent

4 experiments, but presented results are the mean +/- SD of two independent experiments 5 performed in duplicate. $* * *$ means a $\mathrm{p}$ value below 0.001 .

6 
2

3 1. Graff J, Nguyen H, Yu C, et al. The Open Reading Frame 3 Gene of Hepatitis E Virus Contains a cis-Reactive Element and Encodes a Protein Required for Infection of Macaques. J Virol 2005;79:6680-6689.

2. Rocha-Perugini V, Montpellier C, Delgrange D, et al. The CD81 partner EWI-2wint inhibits hepatitis C virus entry. PLoS ONE 2008;3:e1866.

8 3. Abravanel F, Sandres-Saune K, Lhomme S, et al. Genotype 3 diversity and quantification of hepatitis E virus RNA. J. Clin. Microbiol. 2012;50:897-902.

4. Sayed IM, Verhoye L, Cocquerel L, et al. Study of hepatitis E virus infection of genotype 1 and 3 in mice with humanised liver. Gut 2017;66:920-929.

5. Barthe $\mathbf{P}$, Veyron-Churlet $\mathbf{R}$, de Visch A, et al. Mycobacterium tuberculosis LppM Displays an Original Structure and Domain Composition Linked to a Dual Localization. Structure/Folding and Design 2016;24:1788-1794.

6. Gallien S, Perrodou E, Carapito C, et al. Ortho-proteogenomics: Multiple proteomes investigation through orthology and a new MS-based protocol. Genome Research 2008;19:128-135. 
A
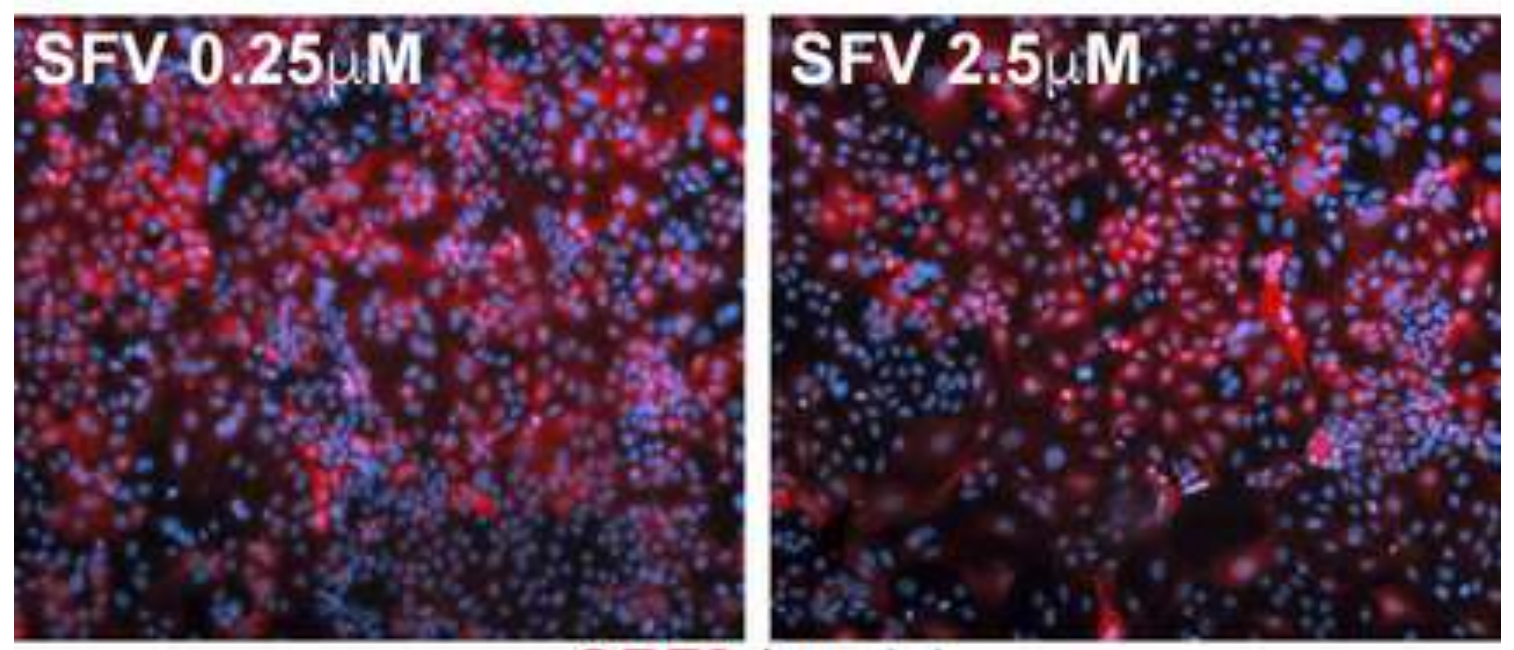

ORF2/ nuclei
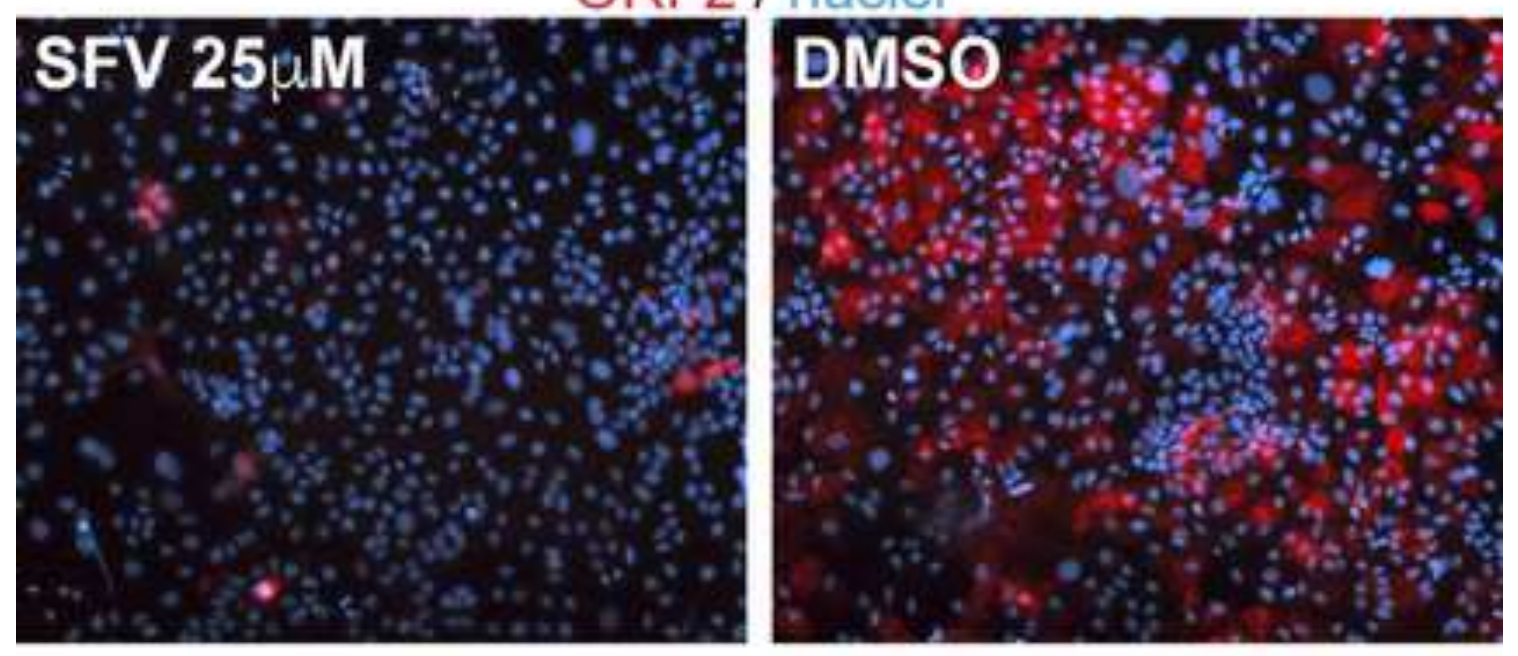

B

PLC3/HEV-p6

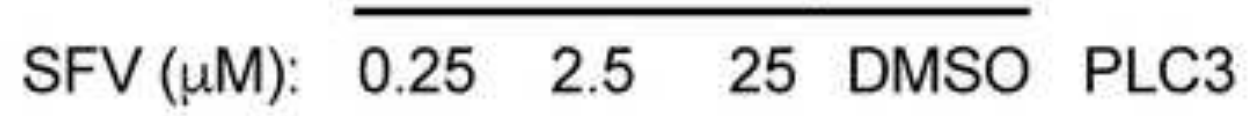

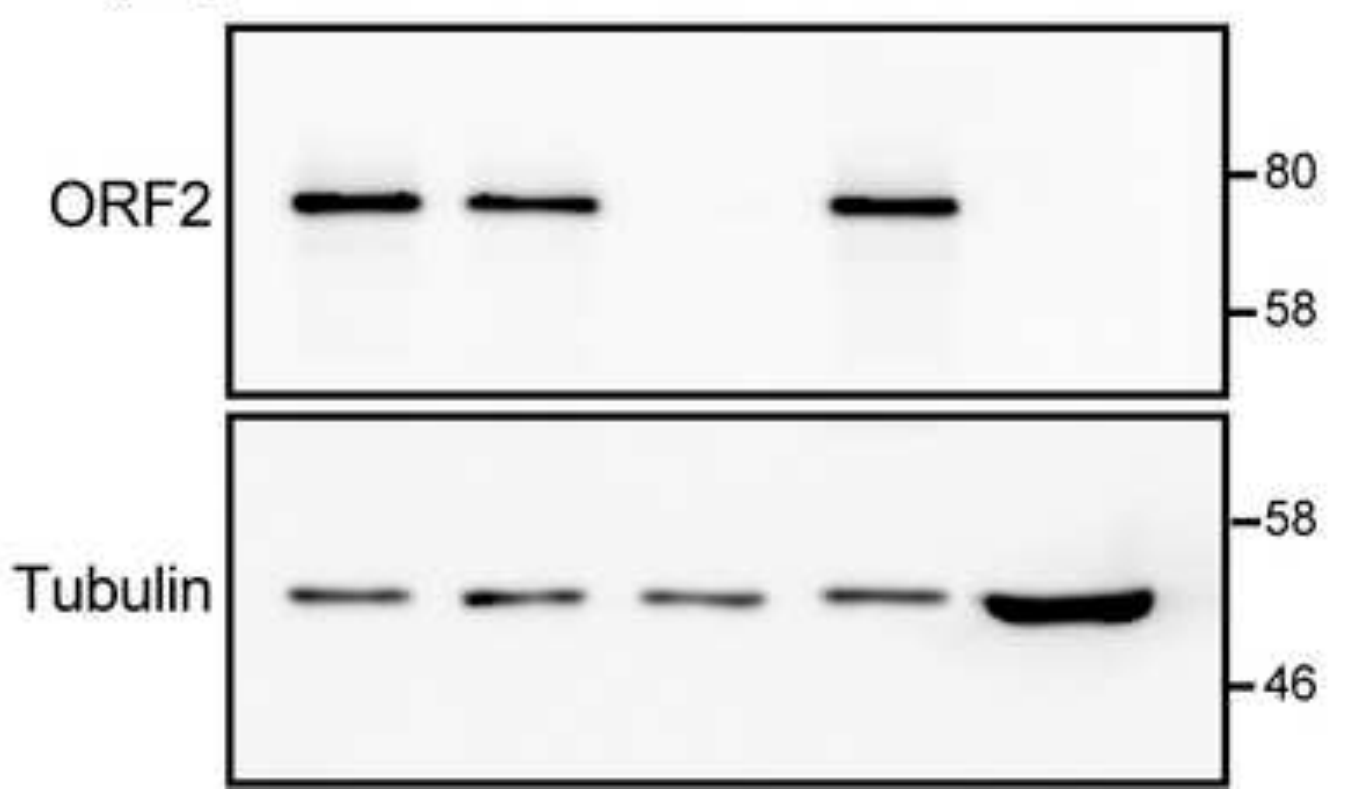




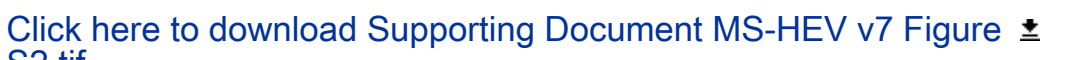
S2.tif

A ORF2i

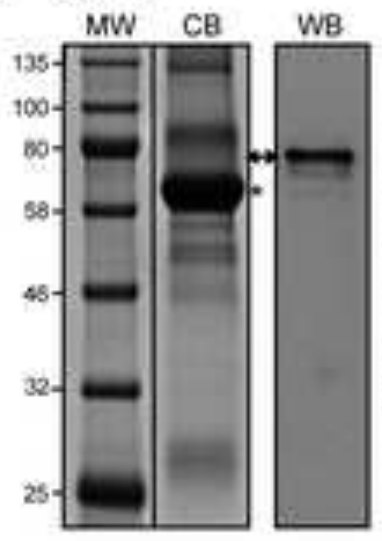

Signal peptide topra

1 MCPRVVLLLF FVFLPMLPAP..PAG9PSGRRR GRRSGGAGGG FWGRRVOSQP is "1 FALPYIHPTN PFAADIVSQS GAGTRPRQPR RPLGSAWRDQ SQRPSAAPRR TON OH RSAPAGAAPL TAVSPAPOTA PVPOVDSRGA ILRRQYNLST SPLTSSVASG ID जT TNLVLYAAPL NPLLPLQDGT NTH IHATEAS NYAQYRVVRA TIRYRPLVPN $D$ a AVGGYAISIS FWPQTTTTPT 5VOMN5IIST DVIILVQPGI ASELVIMSEH 28 2I LHYRNQGWRS VETTGVAEEE ATSGLVMLCI MGSPYNSYTN TPYTGALGLL 200 301 DFALELEFRN LTPGNTNTRY SRYTSTARHR LRRGADGTAE CTTAAATREX MO 35 KOLHFTGTNG VETVGRGXAL TLFNEADTLL GGLPTELISS AGGQLFYSRP 400

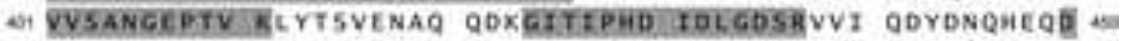
ASI RPTPSPAPSR PFSVLRANOV LWLSLTAAEY DQATYGSSTN DMYVSDTVTF m 20I VNVATGAQAV ARSEDKSKVT LOGRPLTTHQ QYSKTFYVLF LRGKLSFWFA IW

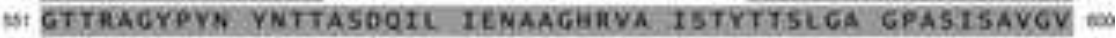
w CAPHSALAVL EDTYOYPARA HTFDDFCPEC RTLGLQGCAF QSTIAELQRL WT KTEVGKTRES at

\title{
B ORF2g
}

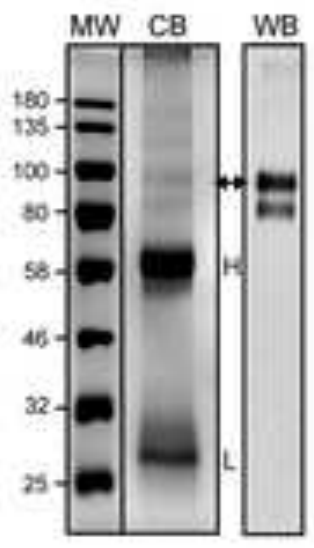

\begin{abstract}
1, MCPRVVLLLF FVFLPMLPAP PAGQPSGRRR GRRSGGATGG: FMGORYOSQP w

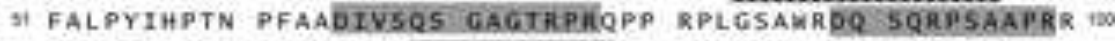
ज RSAPAGAAPL TAVSPAPOTA PVPOVDSRGA ILRRQYNLST SPLTSSYASG 19 5) TNLVLYAAPL NPLLPLQOGT NTHIMATEAS NYAQYIRVRA TIRYRPLVPN 200 221 AVGGYAISIS FWPQTTTTPT SVDMNSTIST DVRTLVQFGI ASELVIPSER MO 2A LIYRNQGNRS VETTGVAEEE ATSGLVMLCI HGSPVNSYTA TPYTGALGLL YO

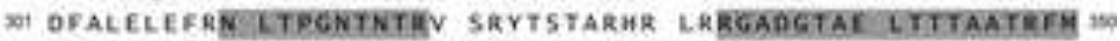

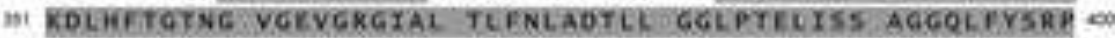
at VUSANCEFTV KLYTSVCNAQ QDKCITIPAD IDLGDSRVVI QDYDNQWKQD 4s a51 HPTPSPAPSI PESVLRANDV LULSLTAAEY DQATYGSSTN PMYVSDTVTF ND NOI VNVATGAQAV ARSIDWSKVT LDGRPLTTIQ QYSKTFYVLP LRGKLSFWEA aD 50 GTTRAGYPYN XVTTASDQTL TEVAAGHAVA TSTYTFSLGA GPASTSAVGV 00 soi CAPHSALAVL EOTVDYPARA HTFDDFCPEC RTLGEQGCAF QSTIAELQRL SI KTEVGXTRES we
\end{abstract}

\section{ORF2e}

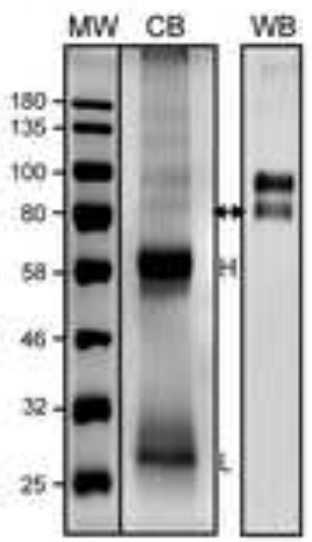

\footnotetext{
Slonal pephidy

1 MCPRVVLLLF FVFLPMLPAP PAGQPSGRRR GRRSGGAGGG FWGDRVDSQP A 31 FALPYIHPTN PFAAOTVSQS GAGTRPRQPP RPLGSAWRDQ SQRPSAAPRR W 99t RSAPAGAAPL TAYSPAPDTA PYPOVDSRGA ILRRQYNLST SPLTSSVASG the 194 TNLVLYAAPL NPLLPLQDGT NTHIMATEAS NYAQYRVVRA TIRYRPLVPN 201 AVGGYAISIS FWPQTTTTPT SVDNNSITST DVR HEVQPGI ASECVIPSER 200 II LHYRNQGWRS VETTGVAEEE ATSGLVMLCI HGSPVNSYTN TPYTGALGLL DO

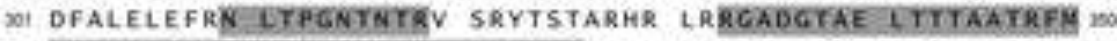
30 KOLMETGTNG VGEVGRGIAL TLERADTLL GGLPTELISS AGGQLEYSRP 400

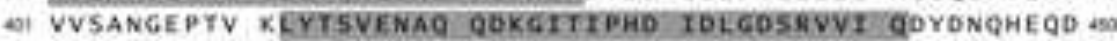
4) RPTPSPAPSR PESVLRANOV LWLSETAARY DQATYGSSTN PNYVSPTVTE 500 SO VRVATCAQAV KRSE OWSKVT LOGRPLTTIQ QVSKTFYVLF CREKLSFWCA = SOI GTTRAGYPYN YRTIASDQRL TENAAGLEVA ISTYTTSLGA GPASTSAVGV mi LAPHSALAVL EDTVOYPARA MTFDDFCPEC RTLGLQCCAF QSTIACCQRE = e) KTIVGKTaES we
} 
Click here to download Supporting Document MS-HEV v7 Figure $\stackrel{ \pm}{ }$ S3.tif

A ORF2I

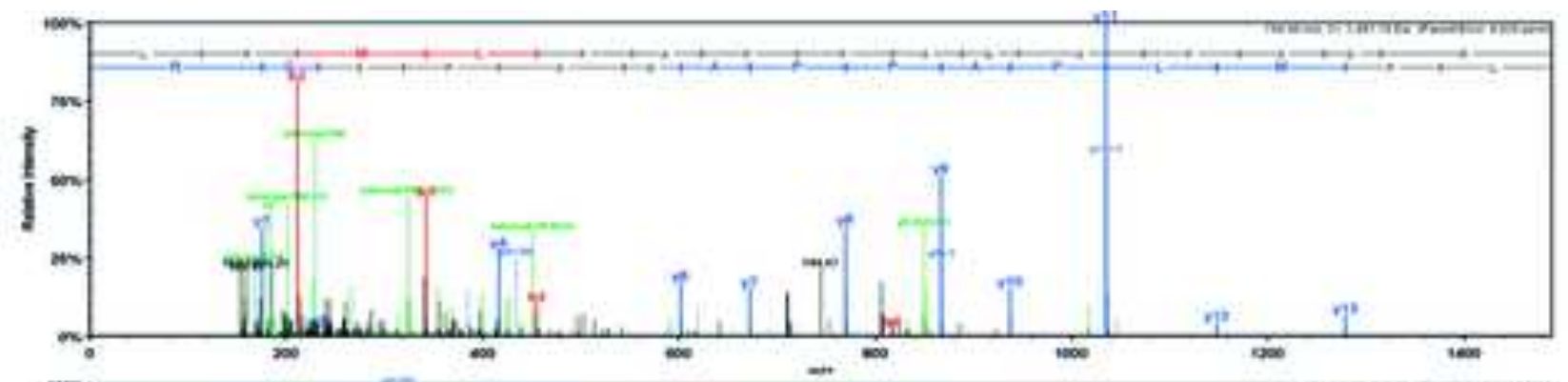

B ORF2i

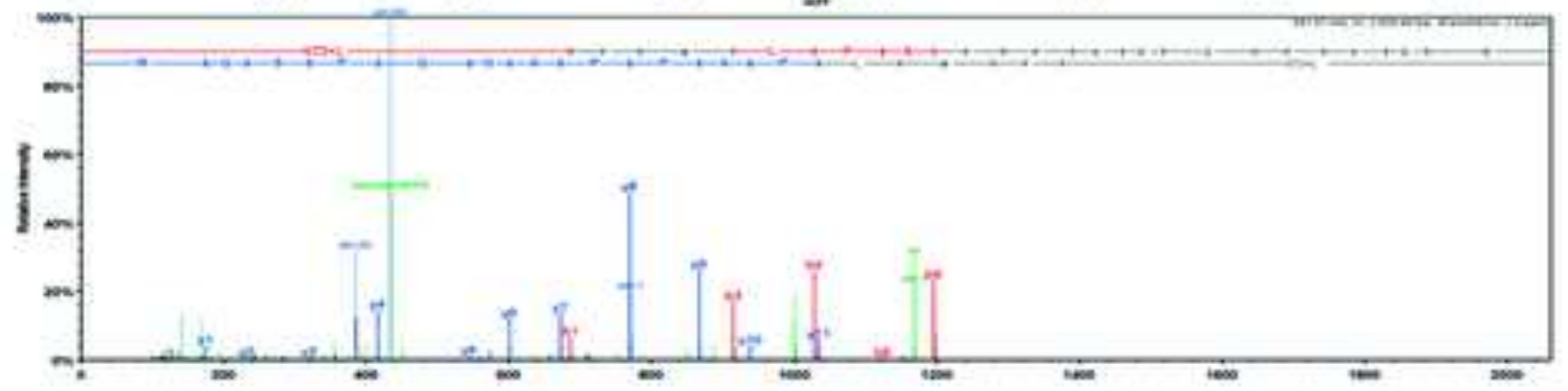

C ORF2g

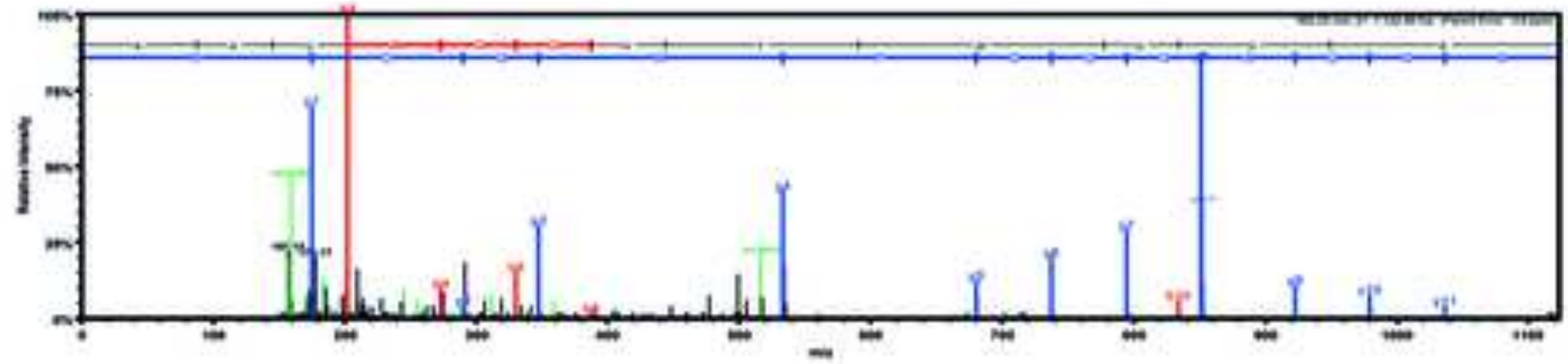

D ORF2g
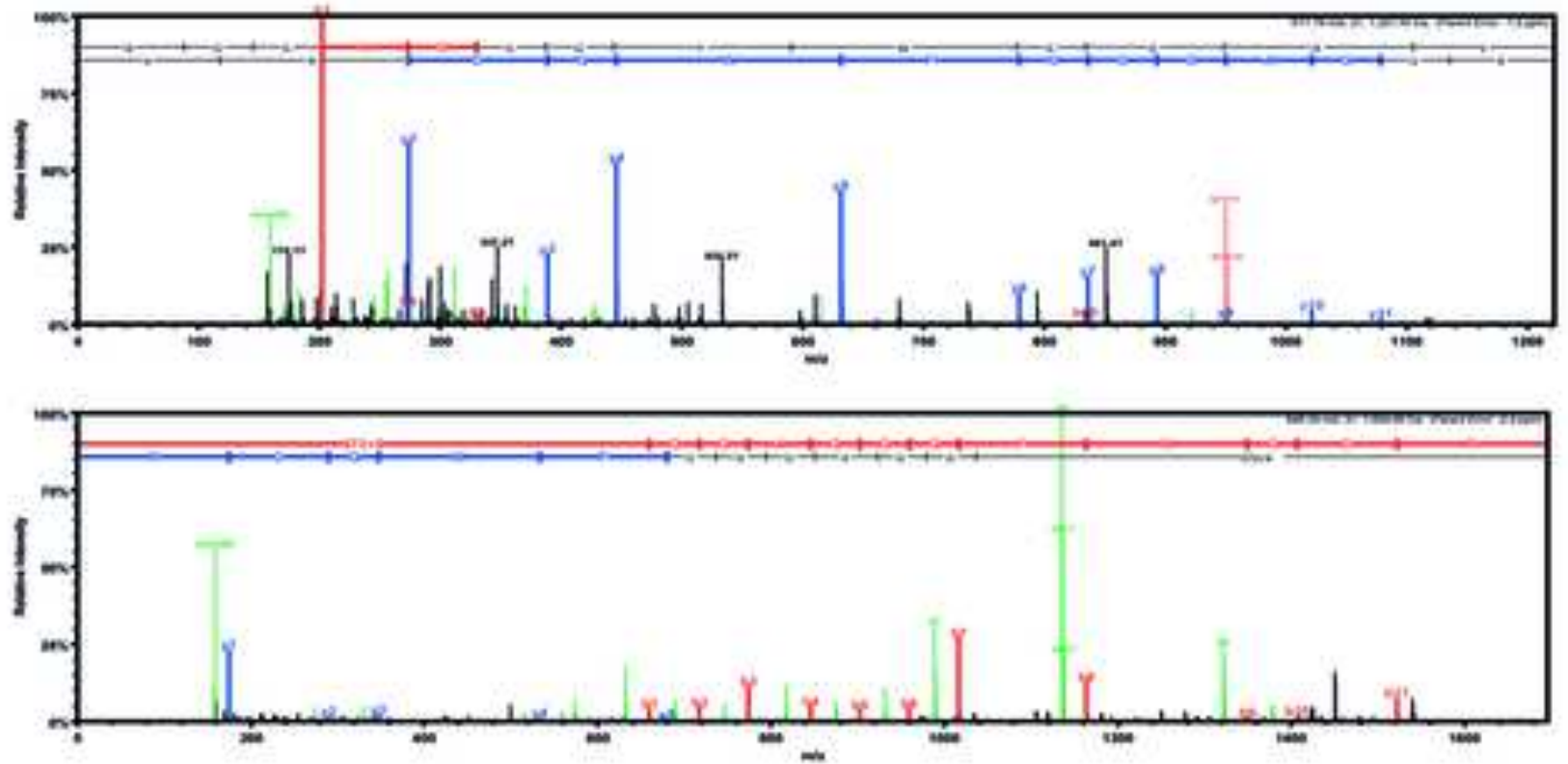

E ORF2g

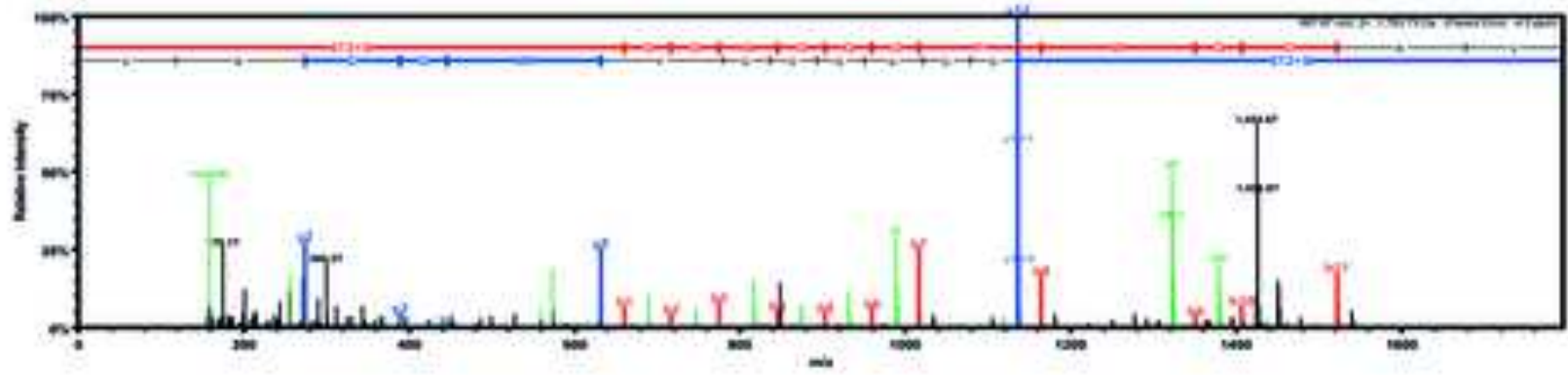

F ORF2g 


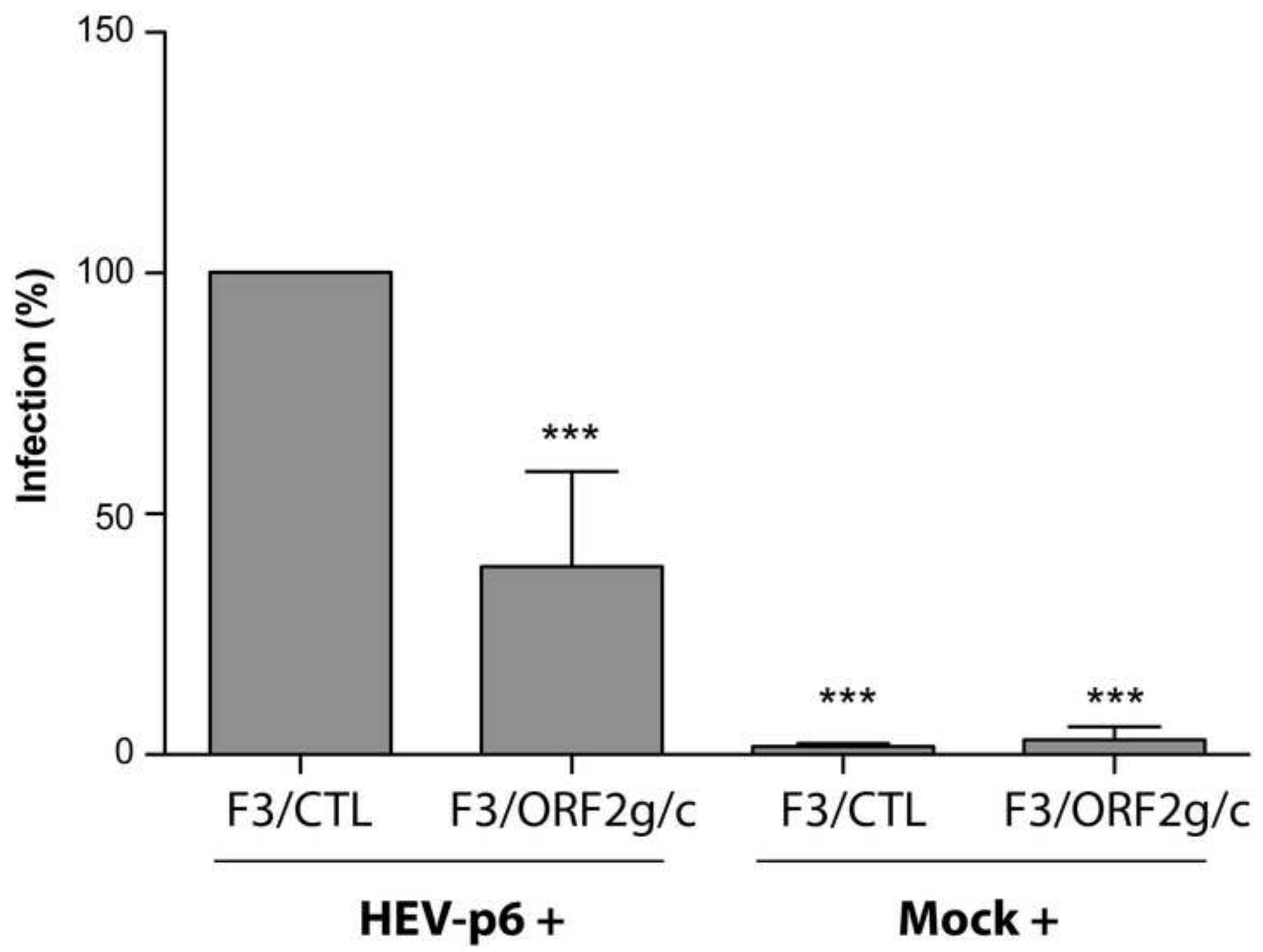

